\title{
Abordagem do ambiente construído da área de vivência pela perspectiva do usuário do canteiro de obras
}

\author{
Approach of the built environment of the living area through the \\ perspective of the user of construction sites
}

\author{
HELOISA NUNES E SILVA \\ Doutoranda, UFSC / PósARQ - Florianópolis/SC, heloisa.nunes@ifsc.edu.br
}

JUAN ANTONIO ZAPATEL

Pós-Doutorado, UFSC/ PósARQ - Florianópolis/SC, juan.antonio@ufsc.br

\section{RESUMO}

O ambiente construído da área de vivência do canteiro de obras possui características peculiares de ambiente provisório, intermitente, diversificado e com variabilidade construtiva, os quais interferem diretamente nas relações entre o ambiente construído e seus usuários, estimados em 2019 sendo 6,5 milhões de trabalhadores vivenciando esse espaço diariamente no Brasil. A legislação que orienta sobre a organização do espaço do canteiro de obras (NR-18) data de 1978 e passa por revisão técnica buscando modernização, uma oportunidade para considerar a temática da ergonomia do ambiente construído da área de vivência do canteiro de obras. Esta pesquisa investiga a percepção ambiental do trabalhador da obra sobre o ambiente construído da área de vivência que utiliza, por meio de Análise Pós-Ocupação em estudo de caso de quatro canteiros de obras na cidade de Criciúma/SC, estruturados em questionários (avaliação orientada pelo usuário) e de visita técnica (levantamento dimensional das instalações, registro fotográfico). Os resultados obtidos demonstram a avaliação do usuário sobre o ambiente da área de vivência, a partir da análise dos fatores: função, forma, luz, som, aeração e temperatura, conforto visual, significado simbólico, e mobiliário de obra disponível. Essas informações foram estruturadas em dados científicos, cuja aplicação incide na perspectiva de subsidiar discussões na revisão da legislação vigente, além de auxiliar tecnicamente o processo de projeto da área de vivência.

PALAVRAS-CHAVE: Ergonomia do ambiente construído, área de vivência, percepção ambiental, canteiro de obras

\section{ABSTRACT}

The built environment in the living area of the construction site has peculiar characteristics of the provisional, intermittent, diversified and constructive variability, which directly interfere in the relationships between the built environment and its users, estimated in 2019 to be 6.5 million workers experiencing this daily space in Brazil. The legislation that guides on the organization of the construction site space (NR-18), from 1978, and undergoes a technical review seeking modernization, an opportunity to consider the theme of the environmental ergonomics created in the living area of the 


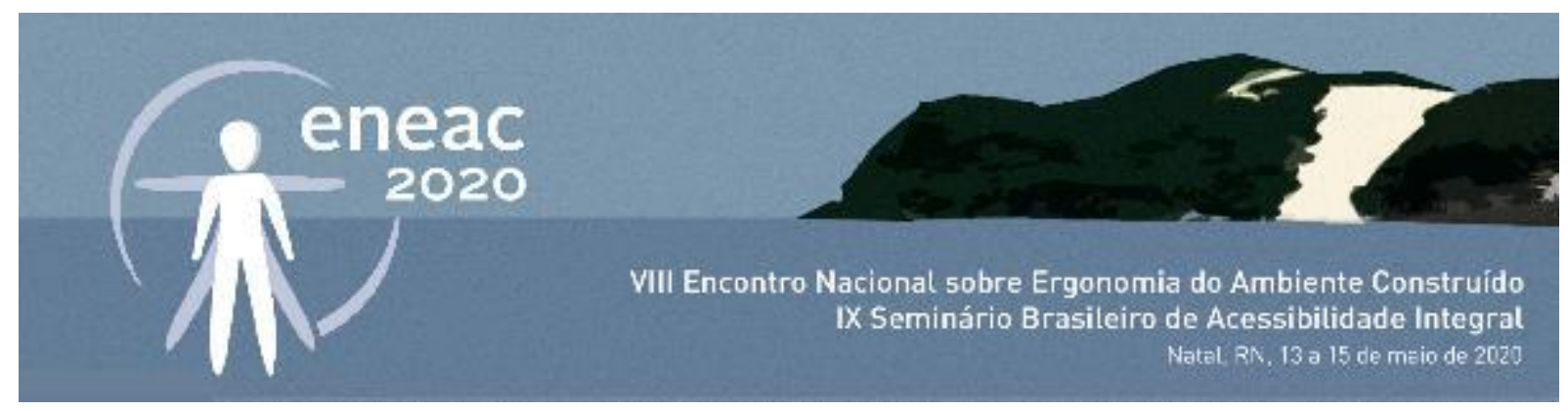

construction site. This research investigates the environmental perception of the construction worker on the built environment in the living area he uses, through the Post-Occupancy Analysis in a Case Study of four construction sites in the city of Criciúma/SC, structured in questionnaires (oriented assessment by the user) and technical visit (dimensional survey of the facilities, photographic record). The results obtained demonstrate the user's assessment of the living area environment, based on the analysis of the factors: function, shape, light, sound, aeration and temperature, visual comfort, symbolic meaning, and available construction furniture. This information was structured in scientific data, whose application focuses on the perspective of supporting discussions in the revision of the current legislation, in addition to technically assisting the project process of the living area.

KEYWORDS: Built environment ergonomics, living area, environmental perception, construction site

\section{INTRODUÇÃO}

A área de vivência é um espaço construído com a finalidade de apoio às atividades de produção em um canteiro de obras. É regulamentada pela legislação da Norma Regulamentadora (NR) nº18 (BRASIL, 1978), que define o Programa de Condições e Meio Ambiente de Trabalho na Indústria da Construção - PCMAT, um documento obrigatório em obras com 20 trabalhadores ou mais, no qual se apresenta o projeto do ambiente construído do canteiro de obras com especificação dos tipos de ambientes, técnica construtiva e local de implantação da obra. Esta norma apresenta uma lista de ambientes necessários, das mínimas condições dimensionais e técnicas relacionadas aos espaços de apoio do trabalhador (área de vivência), definidos em: instalações sanitárias, vestiário, alojamento, local de refeições, cozinha, lavanderia, área de lazer, ambulatório. Assim, a legislação orienta esses ambientes sobre requisitos construtivos específicos e com variação em dimensão física (metragem construída) em função da quantidade de trabalhadores atendidos.

No Brasil, apontam-se dois momentos ímpares no percurso histórico do canteiro de obras, e por conseguinte da área de vivência: a) as condições do canteiro de obras na construção civil até da década de 1970, como o caso da construção de Brasília/DF - entre 1958 a 1960, em que os relatos de Ferro e Arantes (2006) relatam que nenhum canteiro foi tão violento quando aquele, devido à falta de condições ambientais, de higiene, além da falta e organização da empresa construtora em adequar o espaço de produção, de apoio e de moradia dos candangos (nome dado aos trabalhadores oriundos de diversas regiões do país); e b) a criação da legislação da NR-18 em 1978 que estabelece as condições mínimas ambientais da indústria da construção civil, cuja aplicação está em vigor nos dias atuais, evidenciando mais de 40 anos de aplicação, e atualmente em revisão.

Desenvolveram-se pesquisas científicas envolvendo o tema, cujos autores como Rosso (1980), Melhado (1994), Ferreira e Franco (1998), Espinoza (2002), Saurin \& Formoso (2006), em linhas gerais, abordam sobre a organização do espaço de produção da indústria da construção civil, focando em métodos de projeto do canteiro de obras considerando tipo de instalações necessárias, localização adequada e grau de conectividade entre estes elementos, etapas de evolução do canteiro de obras, sistemas construtivos e otimização de custos. Dentro desse viés de engenharia de produção, continuam incipientes as pesquisas envolvendo a temática da percepção ambiental do trabalhador da construção civil em relação ao espaço da área de vivência diante desses progressos produtivos do setor. 


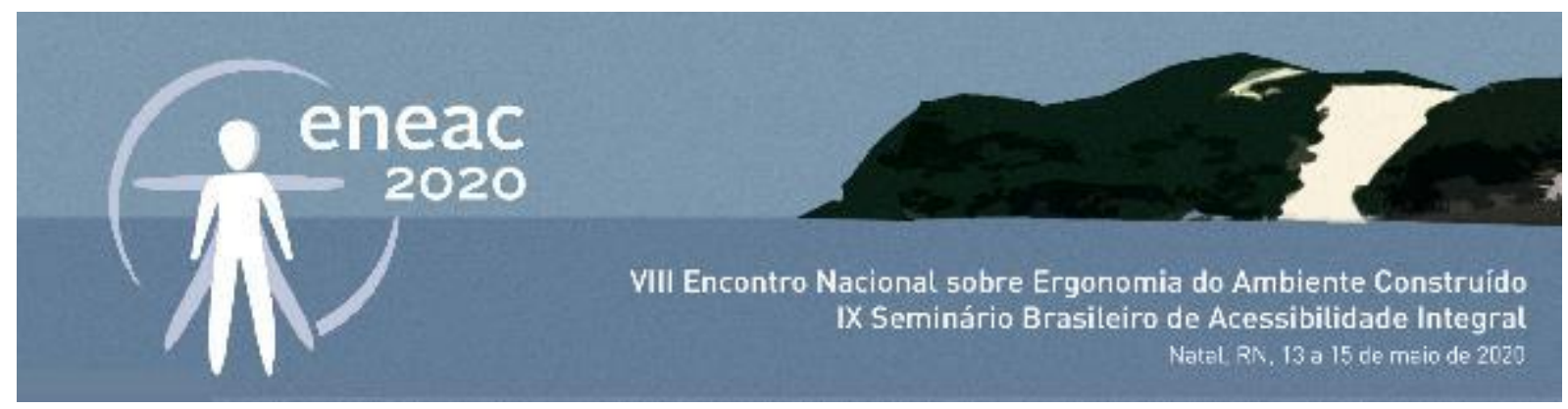

Atualmente, a construção civil emprega aproximadamente $7 \%$ da população ocupada do Brasil, algo em torno de 6,5milhões de trabalhadores, segundo dados do IBGE (2019) referentes ao trimestre de março/abril/maio de 2019. O canteiro de obras é o local de trabalho desse grande público, cujo ambiente construído possui características peculiares por ser provisório (dura o tempo daquela obra), intermitente (devido à diferente localização das obras, ele não é fixo) e diversificado e variabilidade construtiva (trabalhador executa a mesma tarefa em condições ambientais diversas, devido a variabilidade construtiva adotada de cada obra). $O$ aspecto de habitar esse espaço de trabalho na construção civil, que num primeiro momento, supõe-se ser um único espaço construído e fixo, é na verdade de muitos espaços oscilantes, haja vista que cada obra (edificação) possui uma localização única e condições ambientais próprias. Exige-se que o operário vivencie cada obra para executar sua tarefa e usufrua aquele ambiente construído pelo tempo determinado decorrente do tipo de obra. A variabilidade na qualidade do ambiente construído para o trabal ho depende do grau de investimento financeiro da empresa construtora para o canteiro de obras, bem como do cumprimento de legislação específica para a área. A partir do canteiro de obras se estrutura a dinâmica da obra (SILVA,2014), decorrendo disso a maneira como o trabalhador vivência seu ambiente de trabalho.

É neste cenário que se justifica o estudo da ergonomia do ambiente construído da área de vivência, com foco na percepção ambiental do usuário, e assim, auxiliando na coleta de informações atualizadas para servir de apoio nas discussões sobre a revisão da legislação e, consequentemente, na melhoria do ambiente construído para o trabalho na construção civil.

Posto isso, o objetivo desta pesquisa é abordar a percepção ambiental dos usuários da área de vivência em canteiros de obra na cidade de Criciúma/SC e obter a sua opinião sobre a atual condição do ambiente construído vivenciado na obra.

\section{FACES DO AMBIENTE CONSTRUÍDO}

A ergonomia no ambiente construído relaciona o sistema "usuário $x$ tarefa $x$ ambiente", enfocando as caraterísticas relacionados aos aspectos que materializam essa relação, isto é, nos vestígios de humanização, de organização do espaço físcio (lay-out), nos equipamentos e mobiliários disponíveis e nos aspectos de conforto ambiental (térmico, acústico e lumínico)(MONT’ALVÃO, 2011).

Portanto, projetar ambientes para as pessoas envolve uma complexidade de saberes interligados e regulados em causa-efeito no usuário. Para Okamoto (2002) ao se conceber um ambiente construído há que se considerar duas faces de exercício projetual: um lado se organiza o espaço interno do edifício construído, de conotação física do espaço, e no outro a criação do espaço arquitetônico teria de se preocupar com o usuário, com sua percepção e sua maneira de vê-lo, mais do que apenas atender às suas necessidades básicas como repousar, trabalhar, produzir. Ou seja, a face física abrange aspectos materializáveis do ambiente construído, como os requisitos de conforto térmico, acústico, lumínico, dimensionamento, legalidade, normas, técnica construtivas, etc. Na face subjetiva são considerados aspectos de bem-estar, de apropriação do espaço, privacidade, formado pelas sensações e percepções do usuário ao vivenciar o ambiente edificado.

Situações específicas podem influenciar no processo de percepção do ambiente construído pelo usuário, como o uso (funcionalidade do ambiente/espaço construído), o tempo (possibilidade de vivenciar o lugar num prazo de tempo maior/menor) e a escala do projeto (particular/público). É o 


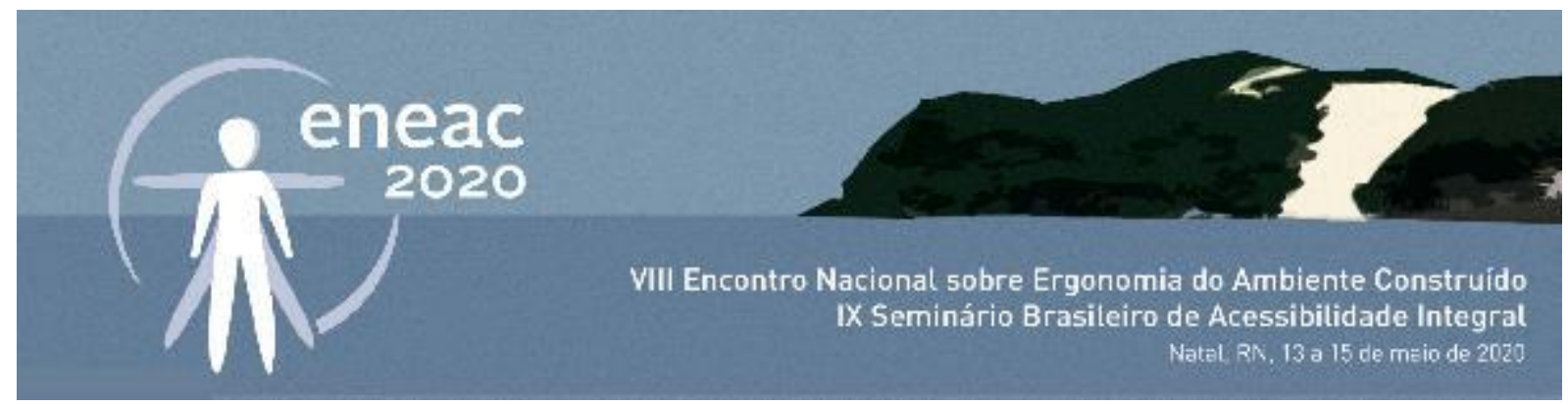

caso do espaço do canteiro de obras, cuja funcionalidade é de local de produção/de trabalho, com tempo de uso determinado pela jornada de trabalho e é um espaço coletivo/vários indivíduos compartilham do local de trabalho. Podem existir facilidades ou dificuldades em se vincular a pessoa ao ambiente construído, seja pelo layout, materiais, dimensão.

Okamoto (2002, p. 37-38) relata sobre o envolvimento do estudo do comportamento humano relacionado ao ambiente construído, a linguagem arquitetônica, significado e valores culturais dado ao espaço e meio ambiente, de modo que a reação aos estímulos ambientais origina, orienta e favorece a qualidade de vida do usuário. Estes fatores de comunicação do ambiente construído são demonstrados na figura 1, sendo: forma, função, cor, textura, aeração/ventilação, temperatura ambiente, significado simbólico, som e luz.

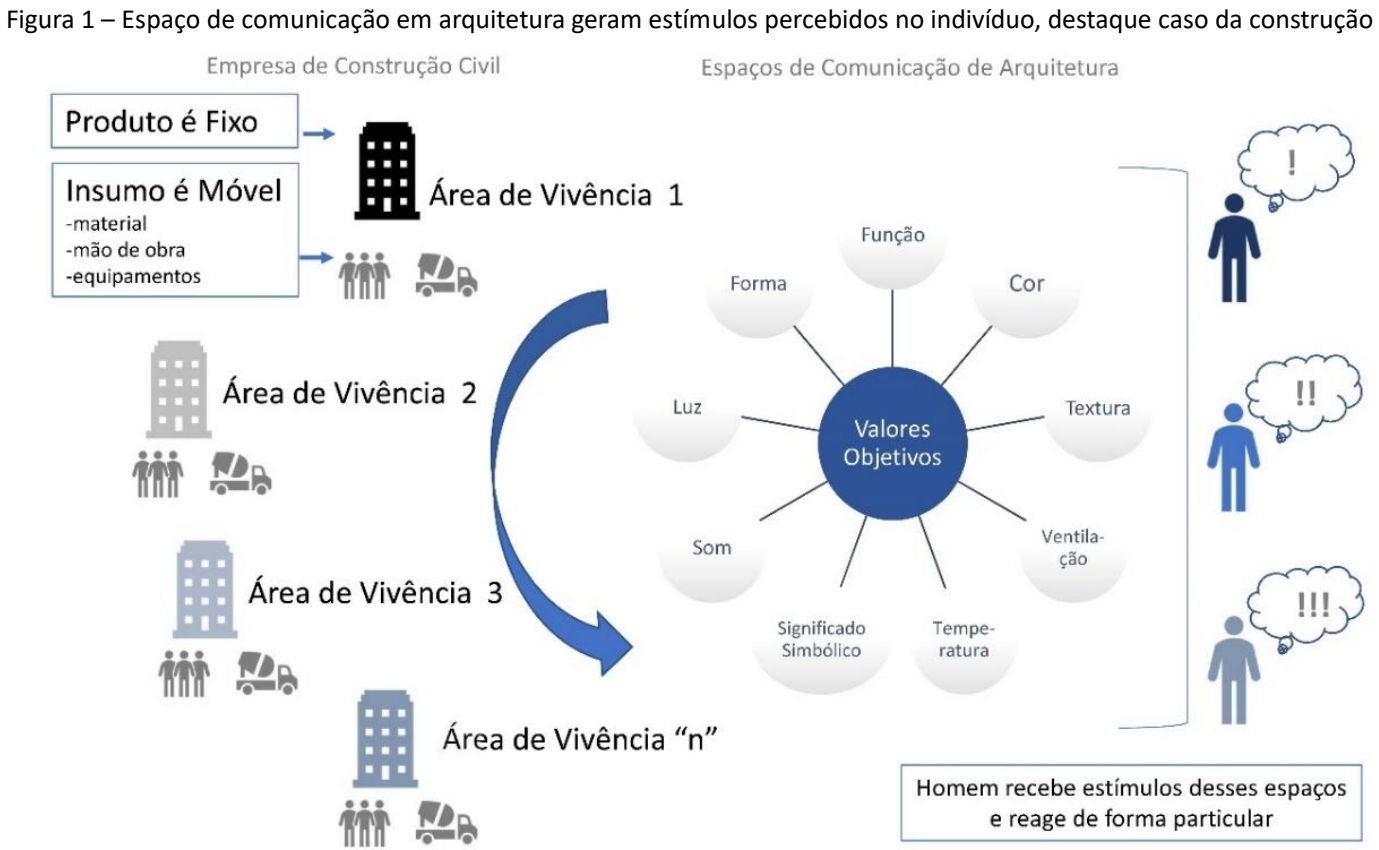

Fonte: Autores,2020.

Cada fator desses constitui-se num dado científico acerca de determinado grupo de pessoas e/ou de ambiente construído. Tal base de dados são orientativos para o processo de projeto do ambiente construído, pois reúne fatores de caráter pessoal e coletivo que impactam neste ambiente para o usuário final.

A base de dados é gerada através de pesquisas que envolvem o usuário no ambiente construído, de modo a captar e reconhecer sua percepção ambiental acerca daquele lugar, tendo como resultado uma medição qualitativa (através de julgamento de valor) dos fatores subjetivos e outra medição quantitativa para os aspectos físicos (índices, valores de medição).

As pesquisas de Ono, Ornstein, Oliveira \& Galvão (2015) demonstram que o processo de produção do ambiente construído necessita de conhecimento pleno de todas as suas etapas, desde as atividades pré-projeto, projeto, construção, uso e ocupação, até o final da vida útil do edifício. Com isso, estabelece-se um ciclo de processo de projeto que busca a melhoria "da qualidade em cada etapa, 


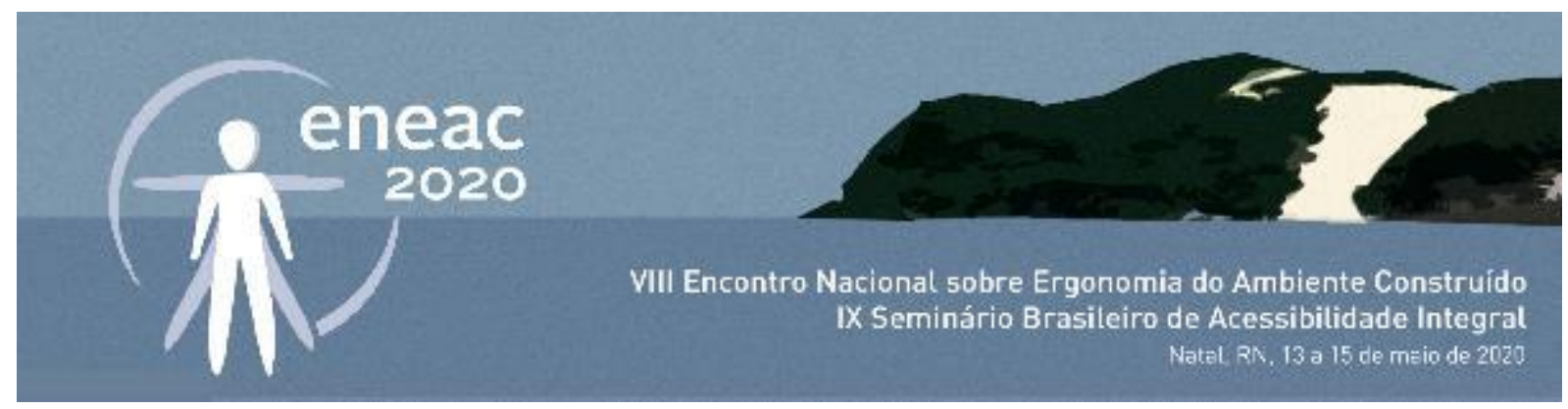

sempre vinculada à redução de erros e associada a custos menores, do projeto ao uso e à manutenção, até o adequado descarte ou reuso dos resíduos da demolição". Mencionam a importância do método da Análise Pós-Ocupação (APO) no sentido de contribuir com o conhecimento detalhado de várias etapas desse processo e por estabelecer a médio e longo prazo, a composição de bancos de dados sobre edificações semelhantes.

\section{MÉTODO}

A pesquisa baseou-se em revisão teórica e estudo exploratório, cujo método adotado foi Avaliação Pós-Ocupação (APO), definido por Roméro e Ornstein (2003) “[...]como uma série de métodos e técnicas que diagnosticam fatores positivos e negativos do ambiente no decorrer do uso a partir da análise de diferentes fatores". Preiser (1988) e Zapatel (1992) orientam que a APO deve ser incorporada ao processo produtivo dos edifícios.

A estrutura de pesquisa baseia-se em estudo exploratório em empresa de construção civil na cidade de Criciúma/SC, abrangendo quatro estudos de caso em obras de edificação residencial multifamiliar, em duas etapas:

a) Etapa Subjetiva: aplicou-se um questionário (avaliação orientada) para os trabalhadores sobre o tempo de profissão na construção civil e acerca da sua opinião da área de vivência instalada, ver figura 2, contendo oito fatores descritos sobre o ambiente construído, baseado em Okamoto (2002, p. 105), e divididos em dois grupos de aspectos da APO, conforme Elali (2006: 2010): a)funcionais relacionados ao aspectos forma, função, som, luz, conforto visual (cor, textura) aeração/ventilação/ temperatura ambiente; e b)comportamentais -significado simbólico e mobiliário de obra* ( *criado nesta pesquisa). Adotou-se a Escala de Lickert para coletar a opinião do usuário, estabelecendo um valor numérico para expressar diferentes percepções sobre o ambiente avaliado, apresentado na figura 2. Considerando a hipótese de todos os fatores avaliados nos ambientes obterem julgamento "ótimo" (nota 4), calculou-se através de média aritmética simples o resultado da avaliação orientada da área de vivência, cujo valor máximo é de 32 pontos. Assim, estabeleceu-se uma relação de percentual de satisfação do usuário em relação ao espaço de trabalho vivenciado (Ex.: 17(valor obtido) $\div 32$ (valos referência máximo) $=0,53$ ou $53 \%$ de satisfação. Os trabalhadores participaram voluntariamente e responderam anonimamente ao questionário impresso (avaliação orientada). Foram reunidos no refeitório da obra no início da jornada de trabalho do turno vespertino (13 horas), onde a pesquisadora esclareceu a atividade, cada participante recebeu um questionário impresso e uma caneta. O tempo de duração da atividade foi de aproximadamente 20 minutos por obra, sendo em dias distinto em cada obra

b) Etapa Física: em visita exploratória fez o registro fotográfico dos ambientes, registro documental dos aspectos construtivos empregados, das medições dos ambientes e elaboração de desenho técnico em software AutoCAD, e de observação visual de uso dos ambientes e sua relação entre si no quesito acessibilidade e lay-out implantado da área de vivência.

A pesquisa delimitou-se em avaliar apenas o ambiente construído da área de vivência instalado nos estudos de caso, bem como o ambulatório não fez parte da avaliação do formulário aplicado devido ao critério adotado nesta pesquisa em avaliar apenas os ambientes da área de vivência de uso habitual e diário pelo trabalhador. . 


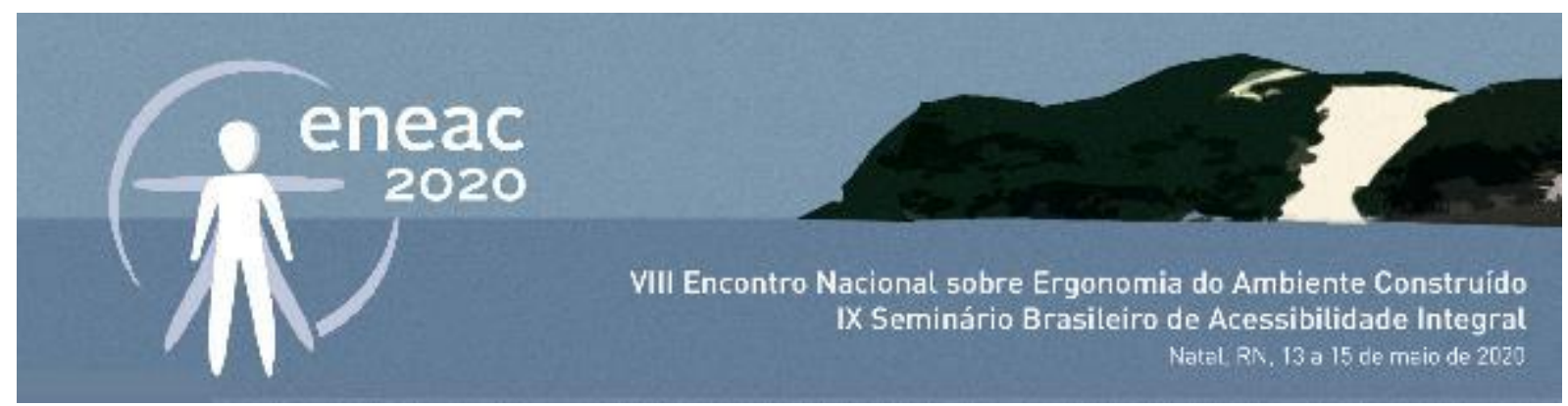

\section{Estudos de Caso em Criciúma/SC}

Foram realizados 4 estudos de caso em obras de construção de edifícios (Figura 3) pela empresa "W" de construção civil da cidade de Criciúma/SC, cuja caraterísticas são de diferentes etapas de execução, com variada tecnologia construtiva empregada na área de vivência de cada obra e de diversos portes de construção (pequeno, médio e grande). Dessa forma, ampliou-se a coleta da percepção do usuário sobre diferentes cenários de ambiente construído de área de vivência. Todas as visitas foram realizadas no mês de maio de 2019 em distintos períodos do dia, sendo realizado a inspeção técnica do ambiente construído da área de vivência na parte da manhã e na parte da tarde a coleta da percepção do usuário sobre o ambiente construído da área de vivência, ver tabela 1.

Figura 3 - Mapa da cidade de Criciúma/SC e a localização das obras A,B,C e D.

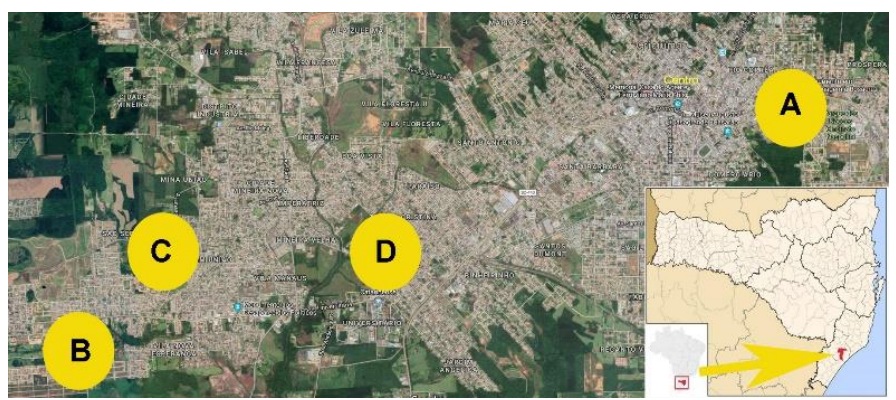

Fonte: Google Maps, 2019. 


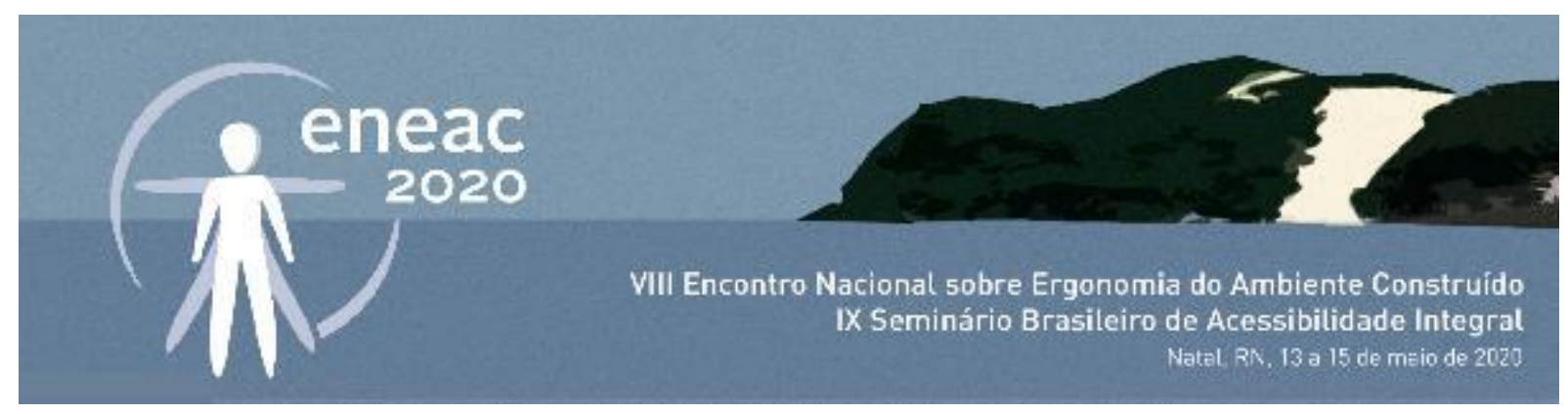

Figura 2 - Esquema metodológico e modelo da avaliação orientada aplicado ao usuário.

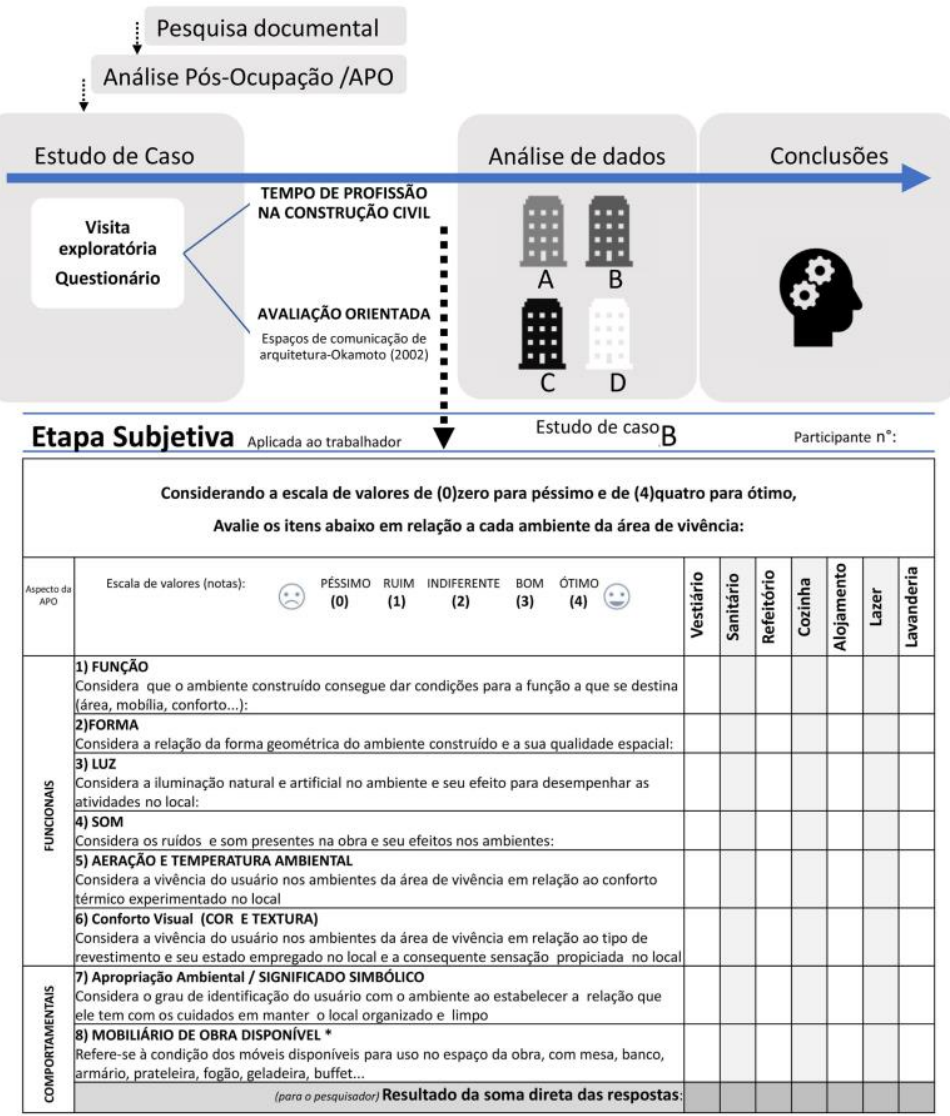

Fonte: Autores,2019.

Tabela 1 - Informações das obras pesquisadas na empresa "W".

\begin{tabular}{|c|c|c|c|c|}
\hline & Obra A & Obra B & Obra C & Obra D \\
\hline Local & Central & Periferia & Periferia & Periferia \\
\hline Bairro & Próspera & São Defende & Mina União & Santa Augusta \\
\hline Porte da obra & $\begin{array}{c}\text { Pequeno } \\
\text { (1 bloco) } \\
10 \text { pavimentos }\end{array}$ & $\begin{array}{c}\text { Grande } \\
\text { (18 blocos) } \\
4 \text { pavimentos }\end{array}$ & $\begin{array}{c}\text { Grande } \\
\text { (25 blocos) } \\
4 \text { pavimentos }\end{array}$ & $\begin{array}{c}\text { Médio } \\
\text { (4 blocos) } \\
9 \text { pavimentos }\end{array}$ \\
\hline Etapa da obra & Acabamento & Fundação / Alvenaria & $\begin{array}{c}\text { Fundação / Alvenaria } \\
\text { / Instalações / } \\
\text { Acabamento }\end{array}$ & $\begin{array}{c}\text { Alvenaria/ } \\
\text { Instalações / } \\
\text { Acabamento }\end{array}$ \\
\hline $\begin{array}{l}\text { Ambientes instalados da } \\
\text { Área de Vivência }\end{array}$ & $\begin{array}{l}\text { Vestiário, Instalação } \\
\text { sanitária, Refeitório }\end{array}$ & $\begin{array}{l}\text { Vestiário, Instalação } \\
\text { sanitária, Refeitório }\end{array}$ & $\begin{array}{l}\text { Vestiário, Instalação } \\
\text { sanitária, Refeitório }\end{array}$ & $\begin{array}{l}\text { Vestiário, Instalação } \\
\text { sanitária, Refeitório }\end{array}$ \\
\hline $\begin{array}{l}\text { Tecnologia construtiva da } \\
\text { área de vivência }\end{array}$ & $\begin{array}{l}\text { Madeira bruta } \\
\text { pintada, placa } \\
\text { metálica, telha de } \\
\text { fibrocimento }\end{array}$ & $\begin{array}{c}\text { Madeira bruta } \\
\text { pintada, telha de } \\
\text { fibrocimento, } \\
\text { alvenaria rebocada, } \\
\text { contêiner (sanitários) }\end{array}$ & $\begin{array}{c}\text { Madeira bruta } \\
\text { pintada, telha de } \\
\text { fibrocimento, } \\
\text { alvenaria rebocada, } \\
\text { contêiner (sanitários) }\end{array}$ & $\begin{array}{l}\text { Madeira bruta } \\
\text { pintada, placa } \\
\text { metálica, telha de } \\
\text { fibrocimento }\end{array}$ \\
\hline Número operários & 20 & 50 & 110 & 60 \\
\hline
\end{tabular}




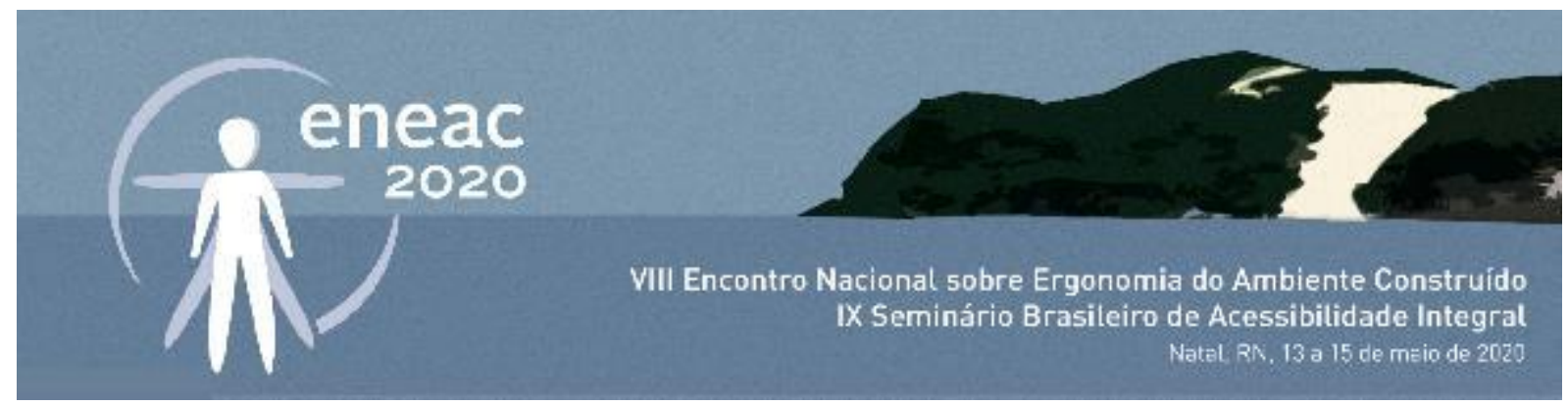

\begin{tabular}{lcccc}
\hline Participantes na pesquisa & 14 & 34 & 83 & 38 \\
\hline $\begin{array}{l}\text { Participantes com } \\
\text { respostas válidas }\end{array}$ & 12 & 29 & 59 & 30 \\
\hline $\begin{array}{l}\text { Tempo de profissão na } \\
\text { construção civil (média) }\end{array}$ & 16,17 anos & 5,81 anos & 8,99 anos & 10,85 anos \\
\hline
\end{tabular}

\section{RESULTADOS E DISCUSSÕES}

Responderam ao questionário 169 trabalhadores das obras visitadas, sendo que as respostas válidas (são os questionários legíveis e preenchidos com respostas conforme solicitado) contabilizaram 130 pessoas, o que representa $77 \%$ da amostra pesquisada.

O tempo de profissão dos trabalhadores na construção civil da amostra era de aproximadamente 10,5 anos, fato indicativo que houve possibilidades anteriores de cada um vivenciar diferentes espaços de área de vivência nos canteiros de obras, e portanto de carregar consigo um conteúdo informativo e personalizado acerca das condições ambientais dessa área, tais como o funcionamento, o conforto, a apropriação do espaço. A partir da aplicação da avaliação orientada, essa experiência individual foi traduzida em valores numéricos de modo apresentar a percepção do trabalhador sobre o ambiente construído da área de vivência, considerando 8 fatores de análise: função, forma, luz, som, aeração e temperatura, conforto visual, significado simbólico, e mobiliário de obra disponível.

De maneira geral, os ambientes das obras obtiveram avaliação positiva, em que consideram a condição do ambiente construído de adequada e boa. Os resultados encontrados basearam-se na média aritmética de todas as respostas válidas dos participantes de cada obra. Pode-se verificar na figura 4 que a análise comparativa entre as áreas de vivência pesquisadas indica que a obra $C$ possui os melhores resultados em relação as demais obras, apontando que a percepção ambiental dos trabalhadores é de maior satisfação com as condições do local. Já com a obra B, há resultados inferiores na avaliação, o que indica uma menor satisfação com a situação da área de vivência existente.

Figura 4 - Gráfico com a comparação dos resultados da avaliação da área de vivência instalada em cada obra pesquisada.

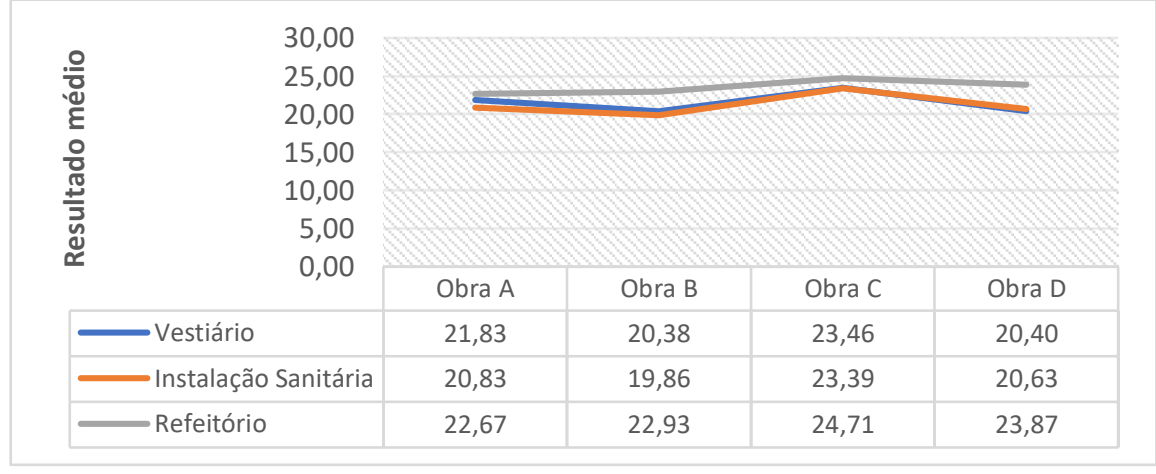

Fonte: Autores, 2019.

Realizado o cálculo da média aritmética dos valores dos três ambientes em cada obra, obteve-se o resultado médio da avaliação de percepção de cada área de vivência, em que a obra A obteve valor de 21,78 pontos, a obra $B$ teve 21,06 pontos, a obra $C$ consegui 23,85 pontos e a obra $D$ resultou em 


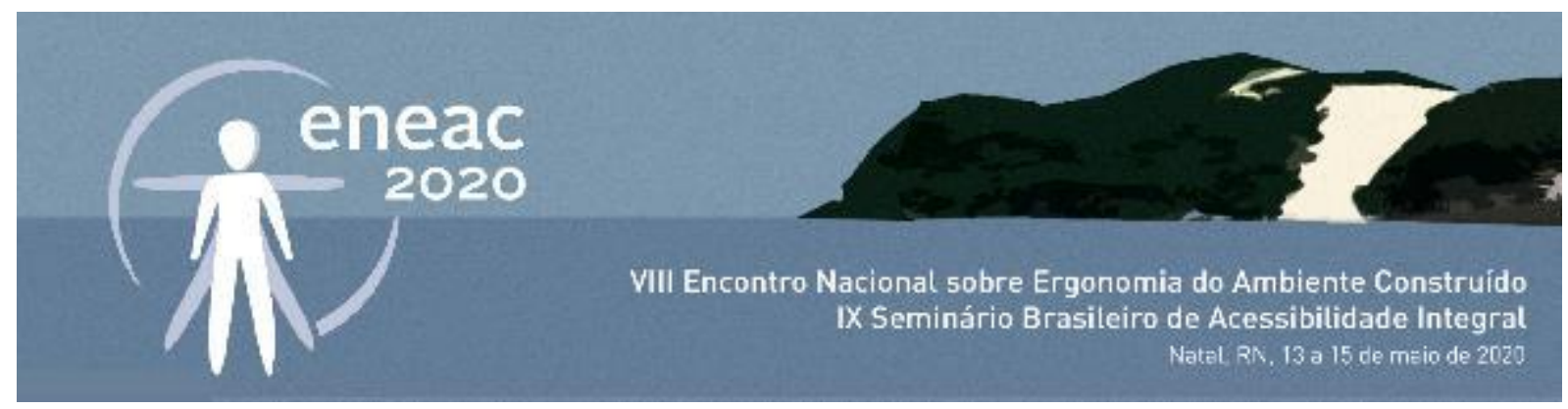

21,63 pontos. Numa relação de percentual de satisfação do usuário em relação ao espaço de trabalho vivenciado, onde há expectativas subjetivas sobre o ambiente construído, os valores dos resultados médio são associados ao valor máximo (de 32 pontos), resultando num dado em porcentagem de satisfação das expectativas subjetivas do usuário sobre o ambiente construído da área de vivência, sendo a obra A de 68,0\%, Obra B de 65,8\%, Obra C de 74,5\% e Obra D de 67,5\%.

O resultado obtido na avaliação pelo usuário sobre o ambiente construído da área de vivência em cada obra é apresentado na tabela 2, em que se pode verificar a proporção dos 8 fatores analisados sobre o resultado obtido. Nota-se que a obra $\mathrm{C}$ possui os valores mais altos na avaliação, no qual o ambiente de maior satisfação de espaço construído é o refeitório, seguido do vestiário e por último a instalação sanitária. As obras B e D obtiveram os menores valores na avaliação, tendo os ambientes de vestiário e instalação sanitário como os mais inadequados ao usuário. A obra A obteve valores próximos da obra $D$, porém apresenta a condição mais crítica de instalação sanitária sobre a ótica do usuário.

\begin{tabular}{|c|c|c|c|c|c|c|c|c|c|c|c|c|}
\hline \multirow[b]{2}{*}{ Fatores } & \multicolumn{3}{|c|}{ Obra A } & \multicolumn{3}{|c|}{ Obra B } & \multicolumn{3}{|c|}{ Obra C } & \multicolumn{3}{|c|}{ Obra D } \\
\hline & V & IS & $R$ & V & IS & $\mathrm{R}$ & V & IS & $\mathrm{R}$ & V & IS & $\mathrm{R}$ \\
\hline Função & 2,92 & 3,08 & 3,33 & 2,45 & 2,52 & 2,86 & 2,86 & 3,03 & 3,19 & 2,30 & 2,43 & 3,13 \\
\hline Forma & 2,67 & 2,67 & 2,83 & 2,28 & 2,28 & 2,97 & 2,66 & 2,90 & 3,03 & 2,23 & 2,10 & 2,90 \\
\hline Luz & 2,92 & 2,42 & 3,00 & 2,59 & 2,48 & 2,72 & 3,14 & 3,08 & 3,25 & 2,73 & 2,80 & 3,17 \\
\hline Som & 2,83 & 2,92 & 2,58 & 2,41 & 2,28 & 2,66 & 2,90 & 2,92 & 2,97 & 2,77 & 2,77 & 2,93 \\
\hline C.Térmico & 2,67 & 2,17 & 2,83 & 2,55 & 2,48 & 2,76 & 2,92 & 2,88 & 3,02 & 2,57 & 2,60 & 2,87 \\
\hline C.Visual & 2,67 & 2,58 & 2,58 & 2,52 & 2,41 & 2,72 & 2,88 & 2,80 & 3,02 & 2,57 & 2,63 & 3,07 \\
\hline Sig.Simb & 2,67 & 2,75 & 2,75 & 2,90 & 2,72 & 3,24 & 3,15 & 2,93 & 3,15 & 2,77 & 2,70 & 2,87 \\
\hline Mobiliário & 2,50 & 2,25 & 2,75 & 2,69 & 2,69 & 3,00 & 2,95 & 2,85 & 3,08 & 2,47 & 2,60 & 2,93 \\
\hline
\end{tabular}

$\mathrm{V}=$ vestiário, IS= instalação sanitária, $\mathrm{R}=$ refeitório

Figura 5 - Imagem do ambiente construído dos vestiários das obras A, B, C e D das obras pesquisadas.
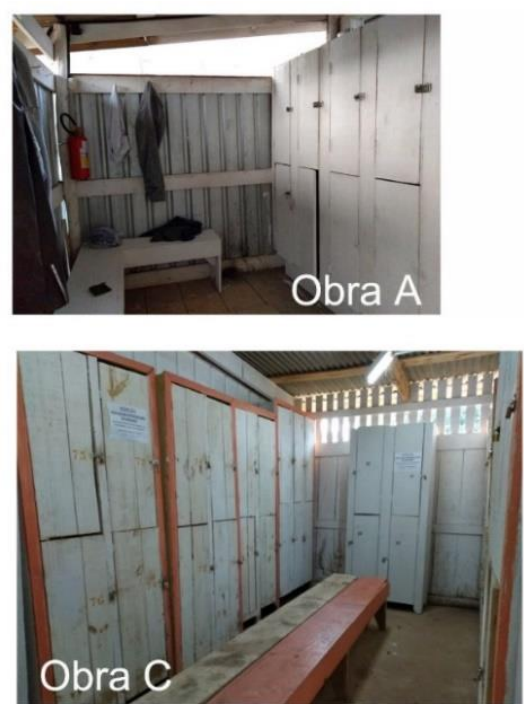
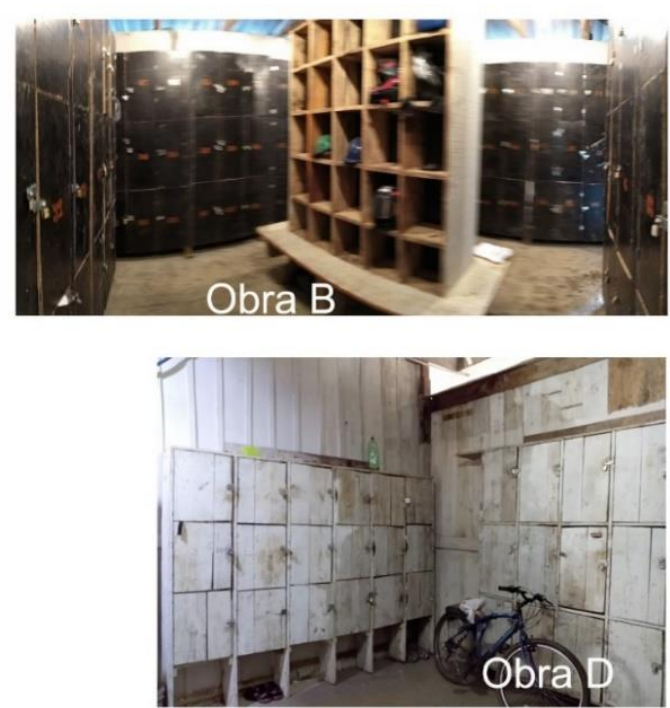

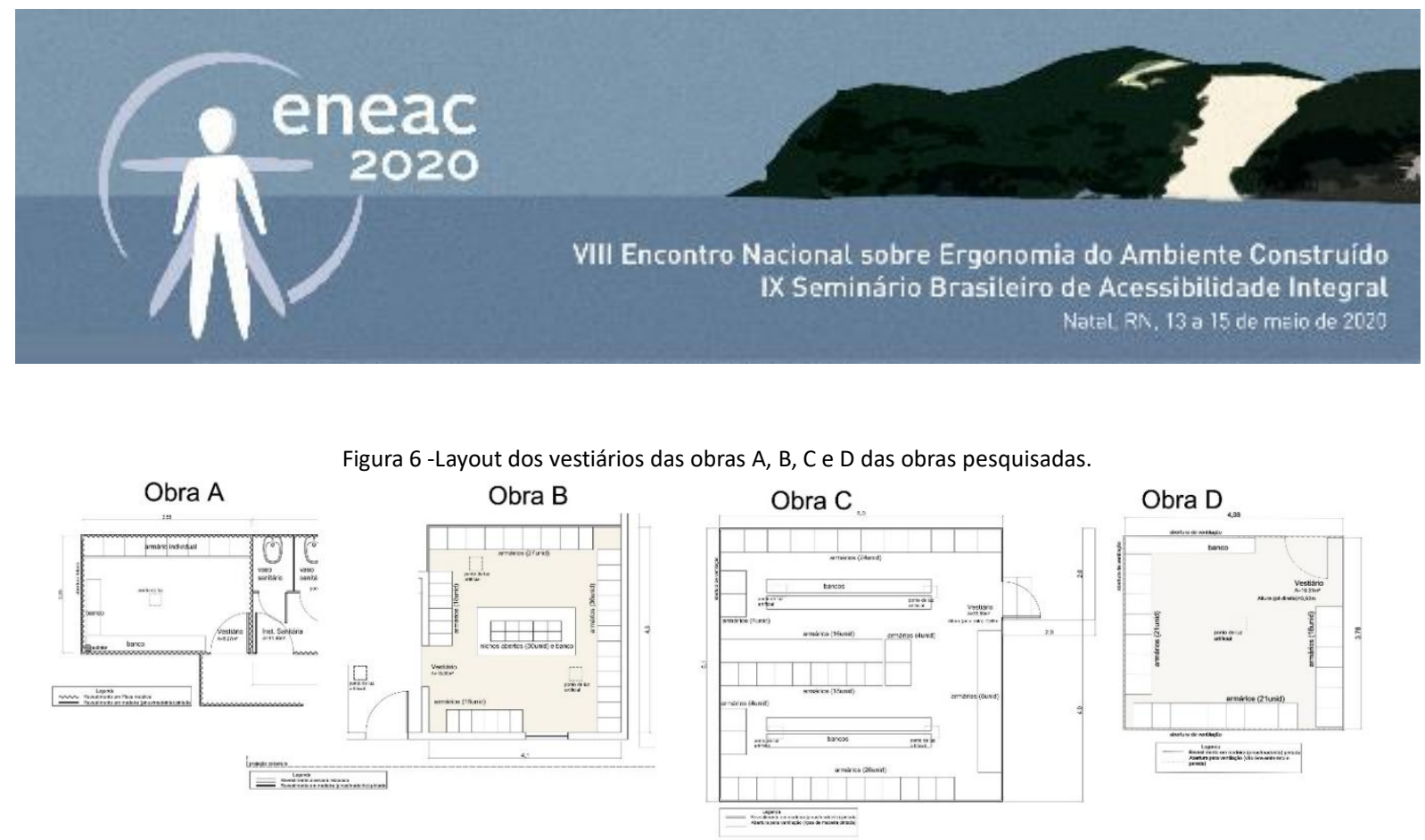

Fonte: Autores , 2019.

\section{Ambiente do Vestiário}

A tecnologia construtiva diferenciada de cada ambiente de vestiário nas obras, bem como seu estado de conservação, refletiu no modo de percepção do usuário, demonstrado por meio dos resultados dos fatores analisados. O layout da área de vivência também impactou sobre essa percepção, conforme relatado na tabela 3 .

A obra A utilizou no ambiente a mistura de painel metálico e madeira bruta (réguas de Pínus) pintado de branco. Nas obras C e D utilizaram apenas madeira bruta (réguas de Pínus) pintado de branco como elemento construtivo do ambiente, e a obra B fez uma associação de alvenaria rebocada e madeira bruta, ambos sem pintura, para o local. Figura 5 e 6.

Tabela 3 - Análise dos resultados verificados sobre o ambiente Vestiário nas obras A, B, C e D.

\begin{tabular}{|c|c|}
\hline Fatores & Análises dos resultados \\
\hline Função & $\begin{array}{l}\text { A localização do vestiário era na entrada da obra e com acesso pavimentado (cimentado) nas } \\
\text { obras } A \text { e } B \text {, já nas obras } B \text { e } D \text { ele estava mais distante, porém ainda próximo da entrada da obra } \\
\text { e com acesso adequado (pedrisco/areia). Apenas na obra } A \text { os ambientes de vestiário e instalação } \\
\text { sanitária eram espaços justapostos, de acesso rápido. Nas demais, estavam distanciados e } \\
\text { requeria deslocamento pela obra. Na obra } D \text {, havia infiltração de água pelo teto e atingia parte } \\
\text { dos armários individuais. } \\
\text { Esses dados tendem a explicar a avaliação do usuário em considerar o ambiente da obra D como } \\
\text { o menos adequado, e as obras A e C como as mais adequadas para o desempenho da função. }\end{array}$ \\
\hline Forma & $\begin{array}{l}\text { As obras A e C são retangulares e com melhor resultado de avaliação, e nas obras B e } D \text { tendem } \\
\text { ao quadrado e com menor satisfação. Observa-se que a percepção dos usuários se estende do } \\
\text { fator função para a forma. }\end{array}$ \\
\hline Luz & $\begin{array}{l}\text { As obras A e C forma mais satisfatórias quanto a percepção de iluminação, enquanto que nas } \\
\text { obras B e D houve menor satisfação, sendo que estas estão localizadas embutidas na edificação } \\
\text { em construção. As obras A e C foram construídas em áreas externas e nos arredores da obra. }\end{array}$ \\
\hline Som & $\begin{array}{l}\text { A obra B obteve menor satisfação quando ao som (e ruído), pois havia grande circulação de } \\
\text { maquinários pesados circundando o ambiente. Nas demais obras, a avaliação foi satisfatória e } \\
\text { similar entre si. }\end{array}$ \\
\hline Conforto Térmico & $\begin{array}{l}\text { As obras A e C foram percebidas como as mais adequadas ao conforto térmico (frio e calor) e } \\
\text { estavam localizadas em construções nos arredores da obra. Nas obras C e D houve menor } \\
\text { satisfação, sendo que estes ambientes se encontram internalizados ao edifício em construção. }\end{array}$ \\
\hline Conforto Visual & $\begin{array}{l}\text { A obras A e C obtiveram a melhor satisfação dos usuários, tendo as vedações laterais e o } \\
\text { mobiliário pintados de branco, em bom estado de conservação e com área espaçosa para circular }\end{array}$ \\
\hline
\end{tabular}




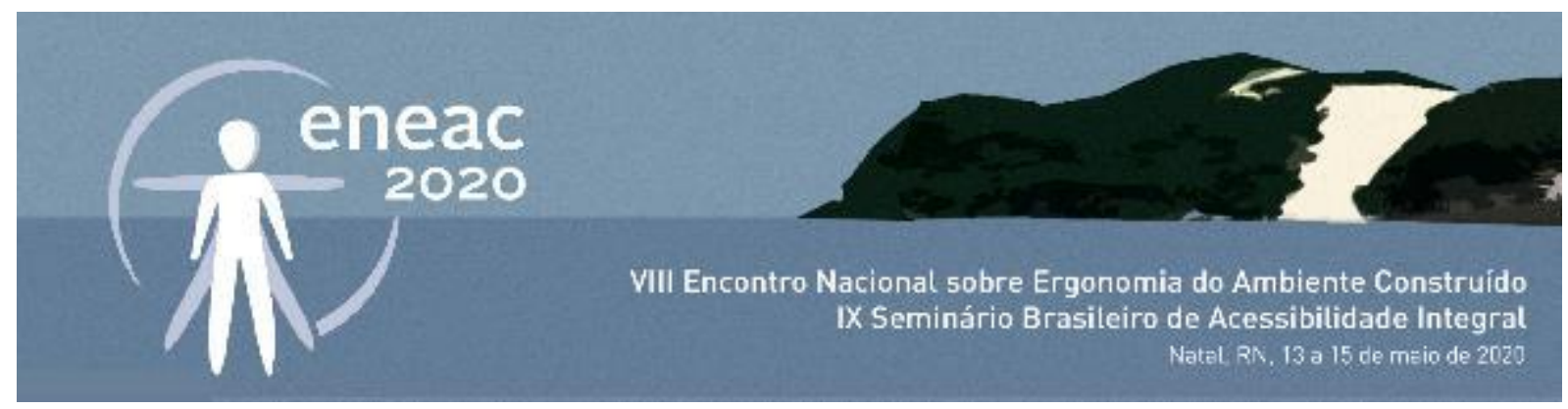

\begin{tabular}{ll}
\hline Fatores & Análises dos resultados \\
\hline & internamente. As obras B e D tiveram avaliação inferior as demais, e o estado de conservação do \\
& $\begin{array}{l}\text { ambiente era inferior ao das outras obras: havia infiltração no teto da obra D e uso da cor preta } \\
\text { (revestimento madeirite naval) nos armário e cinza (reboco aparente) nas paredes ou a madeira } \\
\text { bruta (sem pintura) na obra B. }\end{array}$ \\
\hline Significado Simbólico & $\begin{array}{l}\text { A obra Cobteve maior resultado e indica que o local tem relação de zelo e cuidado pelos usuários. } \\
\text { Em seguida, a obra B e depois a obra D. A obra A apresentou o menor envolvimento de } \\
\text { apropriação com o local. }\end{array}$ \\
\hline Mobiliário & $\begin{array}{l}\text { As obras A e D indicam satisfação menor com a condição e disponibilidade de mobiliário de obra } \\
\text { que em relação a obra B e C. A percepção do usuário indica a obra D como aquela mais } \\
\text { satisfatório nesse tema. }\end{array}$ \\
\hline
\end{tabular}

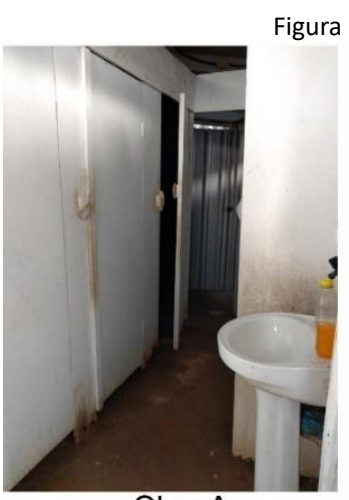

Obra A

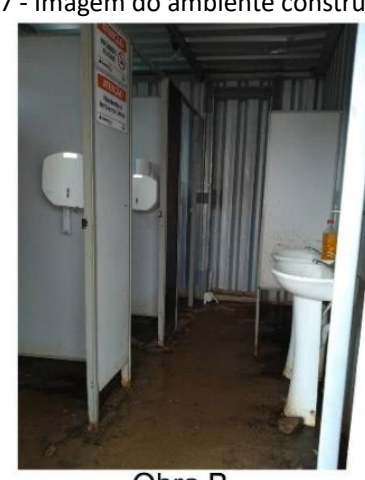

Obra B

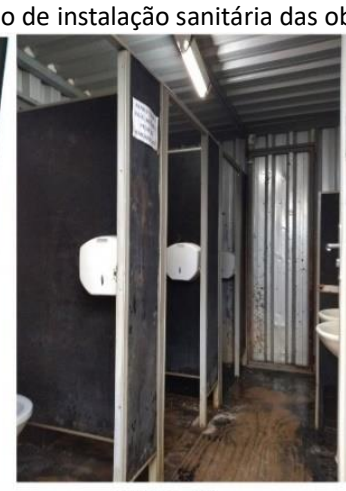

Obra C

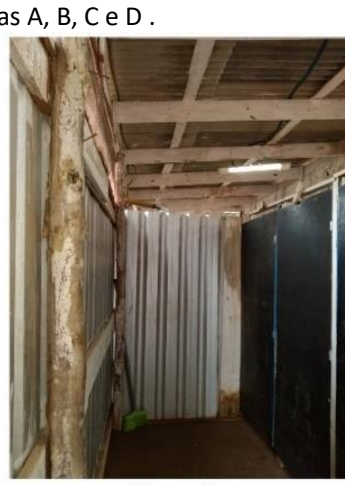

Obra D

Autores , 2019.

\section{Ambiente de Instalação Sanitária}

As obras A e D foram construídas com uso de painel metálico e madeira (Obra A usou chapa de madeirite pintado de branco; Obra D usou réguas de Pinus no estado bruto). Nas obras B e D foram instalados módulos container já adaptados de fábrica para uso de instalações sanitárias. Figura 7 e 8. O layout interno do ambiente e a localização do ambiente em relação aos outros espaços da área de vivência também impactaram sobre a percepção do usuário, e podem ser verificados nos resultados apresentados na tabela 4. 


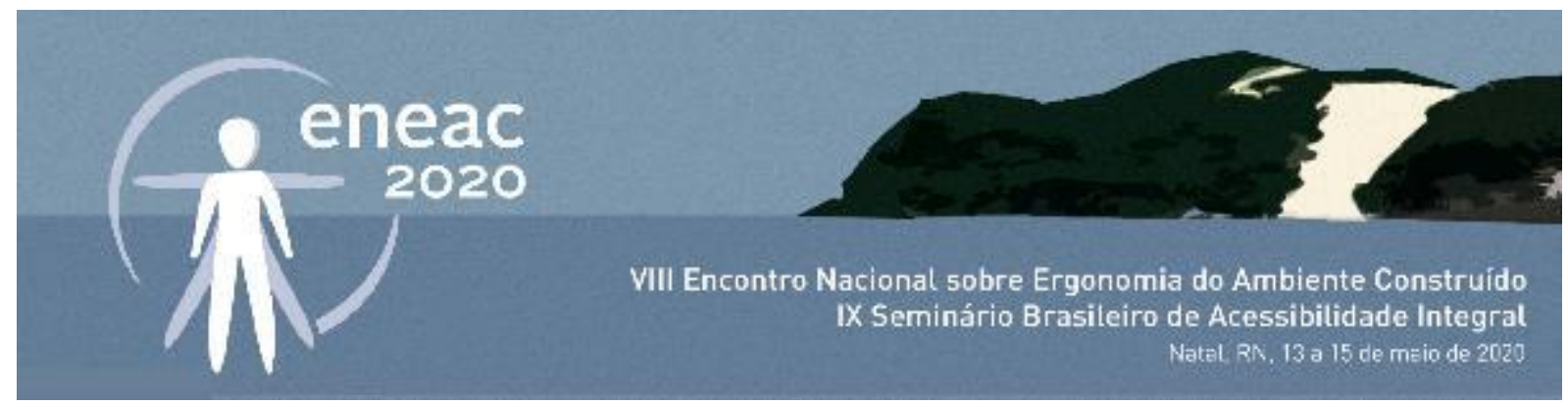

Figura 8 - Layout das instalações sanitárias das obras A, B, C e D das obras pesquisadas.
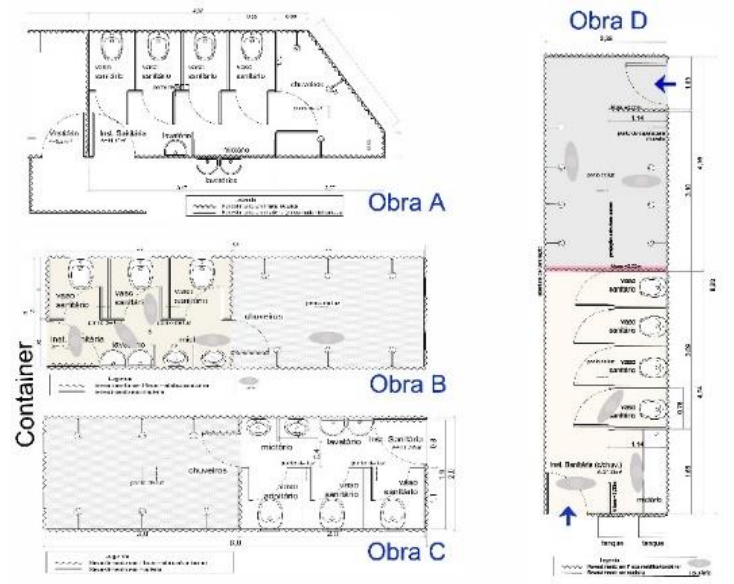

Fonte: Autores , 2019.

Tabela 4 - Análise dos resultados verificados sobre o ambiente de instalações sanitárias nas obras A, B, C e D.

\begin{tabular}{|c|c|}
\hline Fatores & Análises dos resultados \\
\hline Função & $\begin{array}{l}\text { As obras A e C obtiveram melhor resultado na avaliação dos usuários, tendo a localização das } \\
\text { instalações sanitárias bem próximas da entrada da obra e com acessos diferenciado } \\
\text { (pedrisco/areia ou cimentado). As obras B e } D \text { foram consideradas menos satisfatórias, sendo } \\
\text { que a localização dos ambientes era mais distante da entrada da obra e sem acessos tratados } \\
\text { (com contato direto com lama). }\end{array}$ \\
\hline Forma & $\begin{array}{l}\text { A obra D obteve o menor resultado na avaliação, indicando pouca satisfação com o ambiente, } \\
\text { cujo layout (figura 10) é fragmentado em duas áreas internas separadas por uma barreira e induz } \\
\text { a acessos independentes entre área de chuveiros e área de vãos sanitários/mictório. O acesso é } \\
\text { externo e sem tratamento, com contato direto com o solo /lama. A obra B também foi } \\
\text { considerada com menor satisfação, tendo acesso sem tratamento e com contato direto com } \\
\text { lama. As obras B e C são retangulares (utilizam container) e a área útil frequentemente acessada } \\
\text { restringe-se a metade do espaço do módulo container (área de vasos sanitários tem uso } \\
\text { constante, ao contrário da área de chuveiros). Na obra A a forma do ambiente resultou do espaço } \\
\text { disponível no terreno, tendo a área de chuveiros uma condição trapezoidal e com conflitos } \\
\text { internos de uso do espaço. A obra C obteve a melhor avalição em relação as demais, e isso } \\
\text { associa-se a quantidade de container disponíveis em obra ( } 2 \text { unidades), atendendo melhor a } \\
\text { demanda de uso. }\end{array}$ \\
\hline Luz & $\begin{array}{l}\text { Obras C e D foram avaliadas como melhor adequação de luz, e as obras A e B como sendo menos } \\
\text { adequadas. }\end{array}$ \\
\hline Som & $\begin{array}{l}\text { A obra B obteve o menor resultado e indica menor satisfação dos usuários, sendo que o ambiente } \\
\text { está localizado ao lado da circulação geral da obra, que ter trânsito constante de maquinários } \\
\text { pesados (escavadeira, caminhão, etc). Nas demais obras a avaliação resultou em satisfação. }\end{array}$ \\
\hline Conforto Térmico & $\begin{array}{l}\text { O resultado da obra } A \text { indica menor satisfação (local com pouca área de ventilação), enquanto a } \\
\text { obra } C \text { (container) obteve a melhor avaliação. A área de ventilação no ambiente da obra } D \text { era } \\
\text { maior do que as outras áreas, resultando na segunda melhor avaliação. }\end{array}$ \\
\hline Conforto Visual & $\begin{array}{l}\text { Os resultados são similares entre as obras, indicando estarem adequados com a } \\
\text { cor/textura/aparência do ambiente. }\end{array}$ \\
\hline Significado Simbólico & $\begin{array}{l}\text { Em todas as obras há apropriação do espaço pelo usuário, conforme resultados da avaliação. A } \\
\text { obra C obteve o melhor resultado, enquanto as demais foram semelhantes. }\end{array}$ \\
\hline Mobiliário & $\begin{array}{l}\text { As obras B e C obtivem as melhore avaliações, indicando que o uso do módulo container gera } \\
\text { melhor satisfação. A obra A e B tiveram menor nível de satisfação, sendo que a obra A foi a que } \\
\text { obteve o resultado mais baixo de avaliação. }\end{array}$ \\
\hline
\end{tabular}




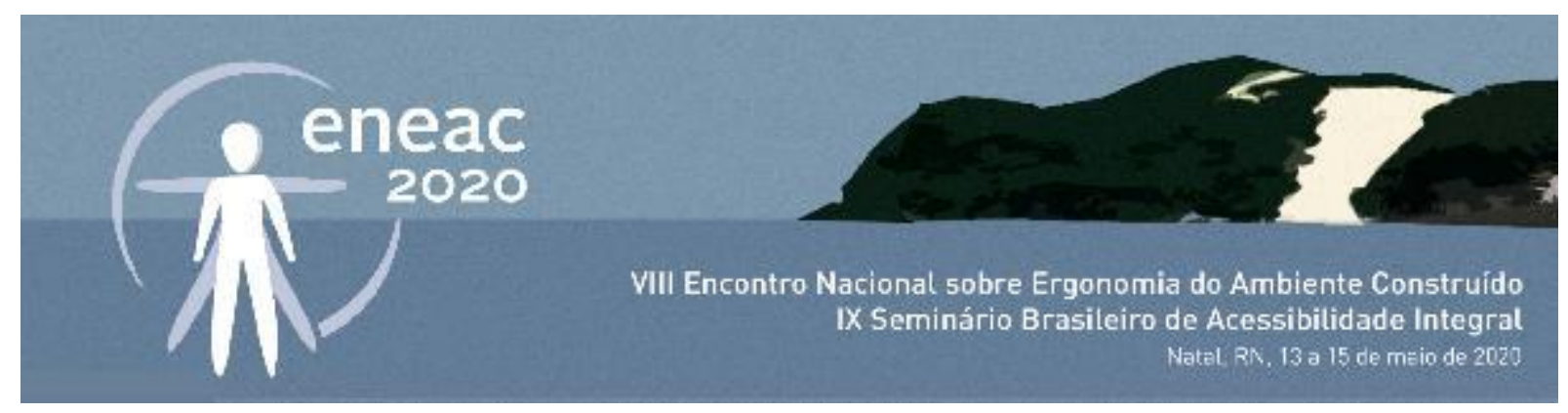

Figura 9 - Imagem do ambiente construído de refeitório das obras A, B, C e D das obras pesquisadas.

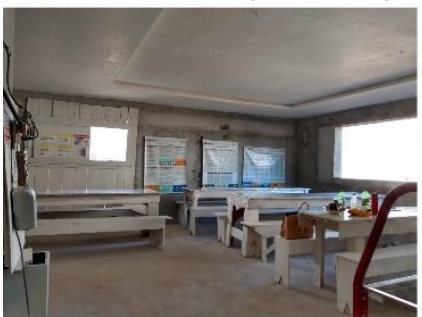

Obra A

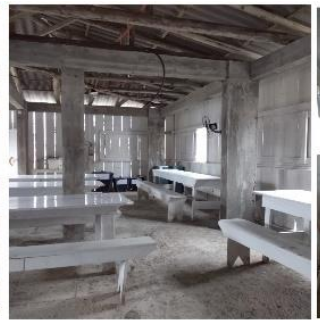

Obra B

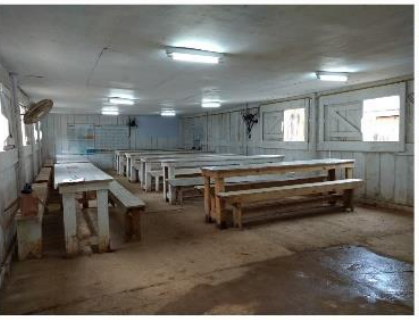

Obra C

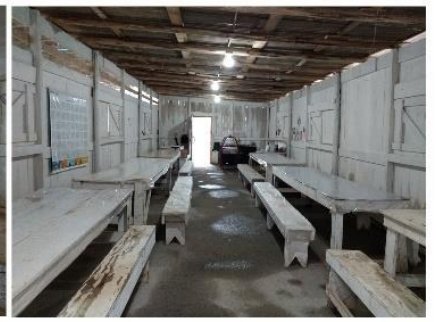

Obra D

Fonte: Autores , 2019.

Figura 10 - Layout do refeitório das obras A, B, C e D das obras pesquisadas.

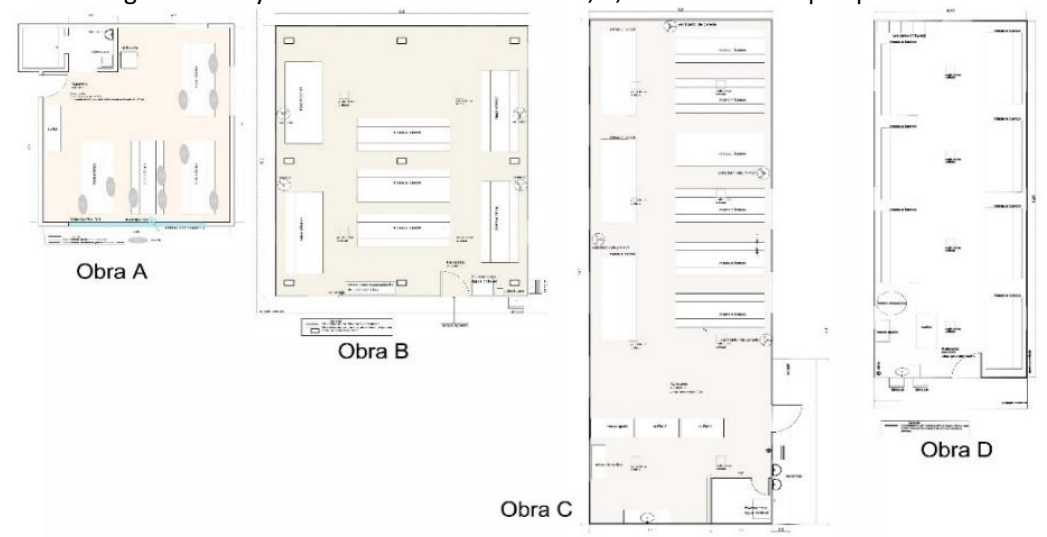

Fonte: Autores , 2019.

\section{Ambiente de Refeitório}

O refeitório da obra A foi associado ao futuro espaço de salão de festas do edifício em construção, sendo as paredes em alvenaria rebocada, teto revestido em gesso, piso cimentado e sem esquadria na abertura. A obra B também fez uso dessa estratégia, e possui vedações lateria em madeira bruta pintada de branco, piso cimentado e cobertura aparente. Nas obras C e D o ambiente foi construído nos arredores do terreno, em espaço próprio e com uso de madeira bruta pintada de branco, piso cimentado, sendo o teto da obra $\mathrm{C}$ em placas de madeirite pintado de branco e na obra $\mathrm{D}$ a cobertura é aparente. Nesta última obra havia furos nas telhas e infiltrações de água pelo telhado. Figuras $9 \mathrm{e}$ 10. Resultados destacados na tabela 5.

Tabela 5 - Análise dos resultados verificados sobre o ambiente de refeitório nas obras A, B, C e D.

\begin{tabular}{ll}
\hline Fatores & Análises dos resultados \\
\hline Função & A obra A teve a melhor avaliação, seguida das obras C e D. O ambiente que obteve menor \\
& satisfação do usuário foi o da obra B. \\
\hline Forma & $\begin{array}{l}\text { Todas as obras obtiveram avaliação de satisfação em níveis semelhantes. A forma predominante } \\
\text { é a retangular, sendo que a obra A aproxima-se do quadrado e obteve os menores resultados de } \\
\text { satisfação em relação as outras obras. }\end{array}$ \\
\hline
\end{tabular}




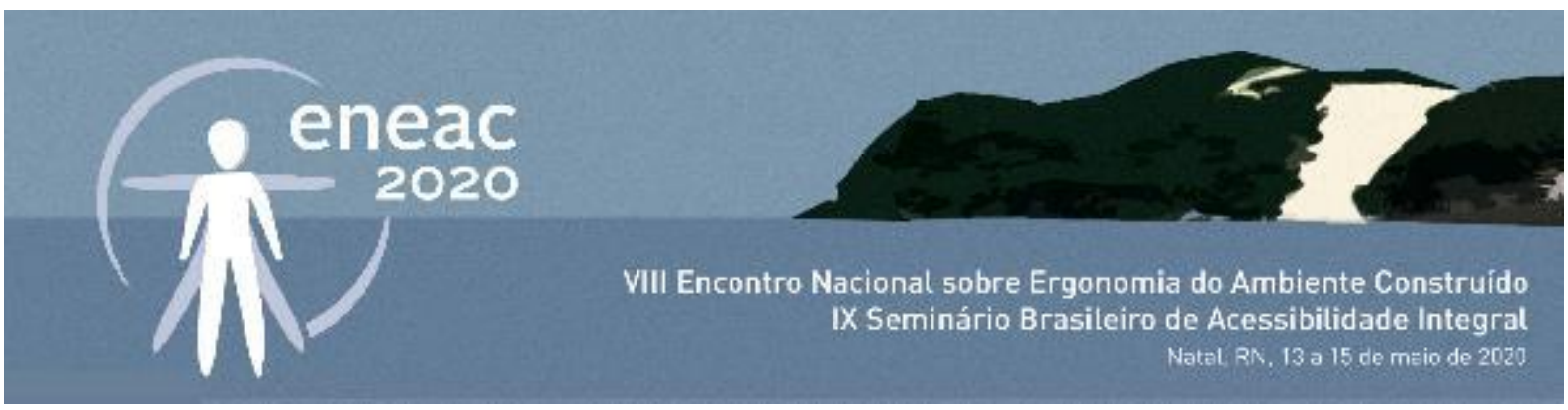

\begin{tabular}{ll}
\hline Fatores & Análises dos resultados \\
\hline Luz & $\begin{array}{l}\text { As obras C e D foram melhores avaliadas, e ambas possuem espaços com muitas } \\
\text { aberturas(janelas). A obra B obteve a menor avaliação devido a problemas no sistema elétrico } \\
\text { do local ( sem energia). }\end{array}$ \\
\hline Som & $\begin{array}{l}\text { As obras C e D obtiveram melhor satisfação do usuário, ambas estão localizadas na periferia do } \\
\text { terreno. As obras A e B tiveram avaliação em menor grau de satisfação do usuário, sendo que } \\
\text { ambas possuem um tamanho menor. }\end{array}$ \\
\hline Conforto Térmico & Todas as obras obtiveram resultados satisfatórios e similares. \\
\hline Conforto Visual & $\begin{array}{l}\text { As obras C e D obtiveram melhor avaliação do usuário, ambas são espaços longilíneos e pintados } \\
\text { em branco. As obras A e B tiveram menor nível de satisfação do usuário, sendo que ambas são } \\
\text { espaços menores e adaptados dos edifícios em construção. }\end{array}$ \\
\hline Significado Simbólico & $\begin{array}{l}\text { As obras B e C possuem os maiores resultados e indicam maior intenção de zelo e cuidado com } \\
\text { o ambiente. As obras A e D obtiveram resultados menores. }\end{array}$ \\
\hline Mobiliário & $\begin{array}{l}\text { A obra A recebeu a menor nota de satisfação, sendo que as demais obras tiveram melhores } \\
\text { resultados, indicando satisfação com o mobiliário disponível em obra. }\end{array}$ \\
\hline
\end{tabular}

\section{Discussões da área de vivência analisada nas obras}

Na figura 11, pode-se verificar que o percurso realizado pelo trabalhador entre os ambientes de vestiário e instalação sanitária (local dos chuveiros) nas obras B, C e D é distante, podendo tornar-se inadequado em relação à função, por expor a privacidade do indivíduo e devido ao acesso sem tratamento (direto solo/lama).

Apenas na Obra A os ambientes de vestiário e instalação sanitária estão justapostos, facilitando o percurso do usuário e mantendo sua privacidade, bem como o acesso é tratado (pedrisco/areia /cimentado). A estimativa do percurso realizado pelo trabalhador entre esses ambientes pode chegar de 40 metros a até 170 metros de distância, conforme a obra. Isso influencia na avaliação do desempenho da função dos ambientes, ver figura 12, em que as obras A e C obtiveram desempenho melhor de satisfação em relação as obras B e D, cujos ambientes se localizavam mais distantes da entrada da obra e afastados em relação um do outro. Observa-se que quanto mais afastados estiverem os ambientes de vestiário e instalação sanitária entre si e da entrada da obra, menor será a satisfação do usuário da obra sobre o desempenho da função desses ambientes.

Figura 11 - Layout da área de vivência de cada obra analisada e o percurso entre os ambientes de vestiário e instalação sanitária, com a distância percorrida estimada no círculo amarelo.

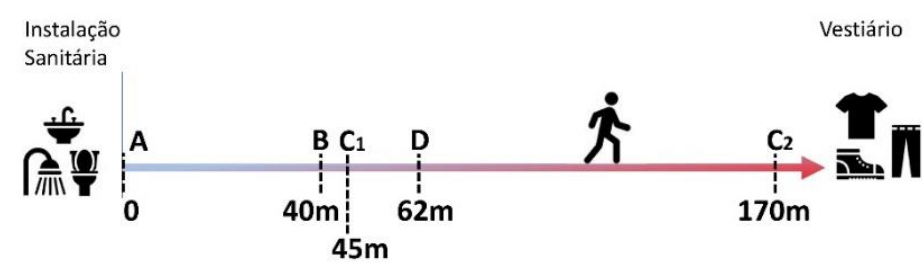




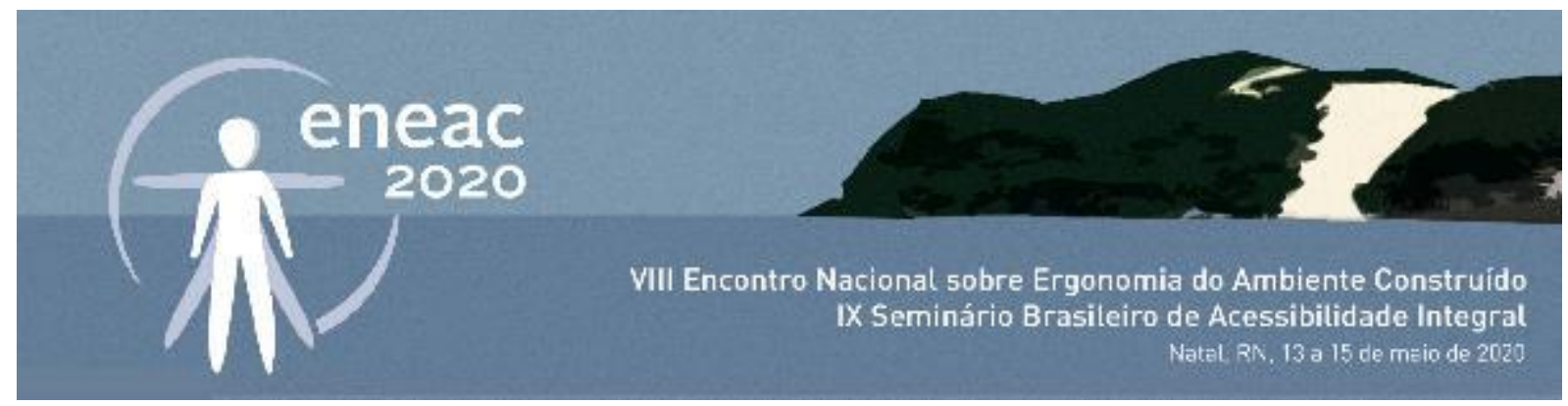

Figura 12 - Gráfico sobre os resultados das avaliações dos usuários sobre o fator função dos ambientes vestiário e instalação sanitária, e sua relação com o percurso simulado entre esses ambientes na obra.

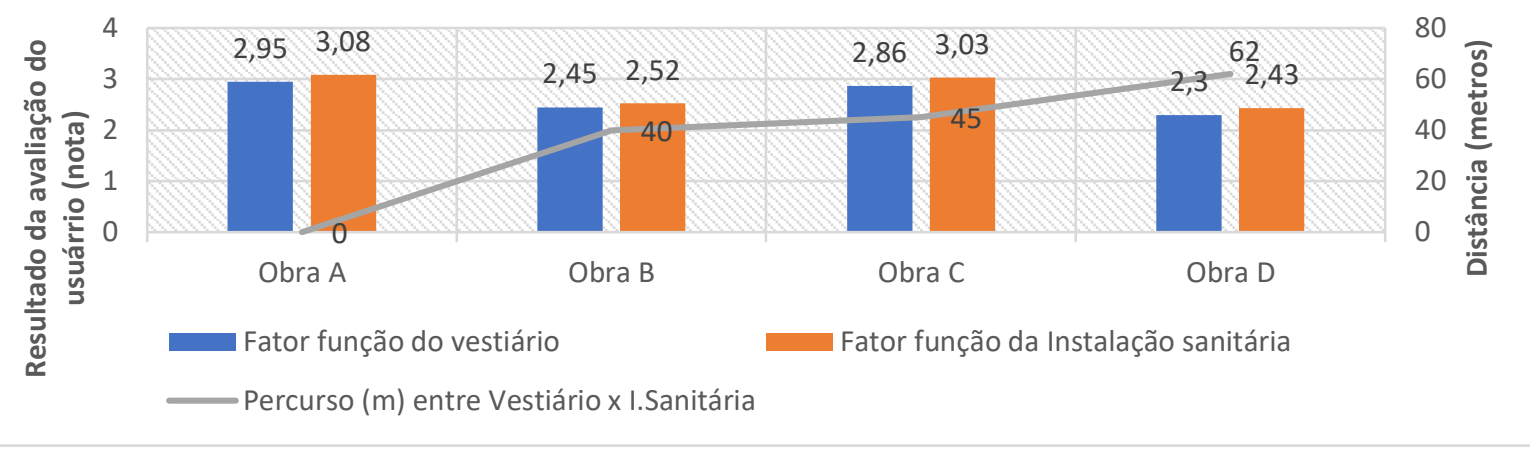

Fonte: Autores , 2019.

A respeito da apropriação espacial, os dados apresentados na figura 13 indicam que em todas as obras pesquisadas o ambiente de instalação sanitária é que menos gera um significado simbólico, isto é, possui menor apropriação espacial pelo usuário e reflete em menor intensidade de zelo e cuidados com o espaço construído. Também se observou que a Obra $\mathrm{C}$ disponibilizou dois módulos container de instalação sanitária e distribuídos em áreas diferente na obra, fato que refletiu na percepção do usuário daquela obra ao apresentar o maior resultado na avaliação desse fator em relação as demais obras. Ou seja, o usuário dessa obra indica ter maior apropriação espacial desse ambiente, motivado pela maior oferta de acesso à instalação sanitária e em diferentes locais da obra, facilitando seu acesso ao ambiente. Também se observa uma tendência de quanto maior o percurso entre os ambientes de instalação sanitária e vestiário, menor foi a relação de significação simbólico (apropriação espacial).

Em relação ao efeito que o tempo de profissão na construção civil (tempo médio) tem em relação à percepção do significado simbólico do ambiente, os dados obtidos indicam que quanto menor esse tempo, maior será a apropriação espacial com o ambiente construído. Figura 13.

Figura 13 - Gráfico dos resultados das avaliações pelos usuários dos ambientes da área de vivência sobre o fator significado simbólico (apropriação) e a relação com o tempo de profissão na construção civil.

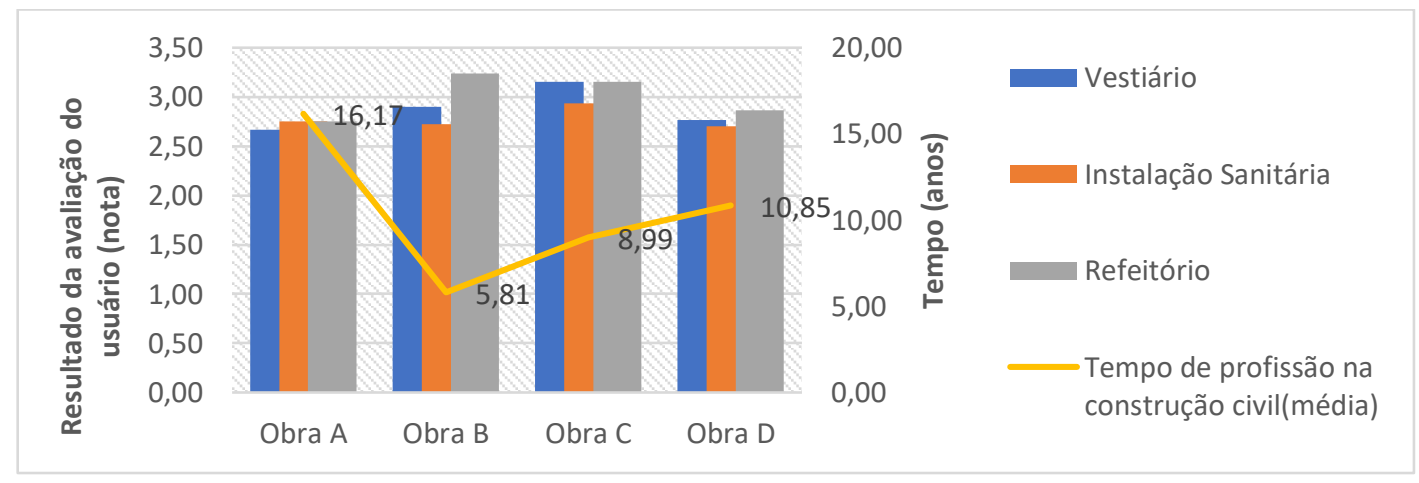

Fonte: Autores , 2019.

Na tabela 6 , considerou-se a ordem decrescente de posicionamento de $1^{\circ}, 2^{\circ}, 3^{\circ}$ e $4^{\circ}$ lugar entre cada ambiente das obras, com a representação da posição 1(= maior valor) a até 4(= menor valor) para 0 valor obtido na avaliação pelo usuário sobre o fator no ambiente. Desse modo, constatou-se que a 


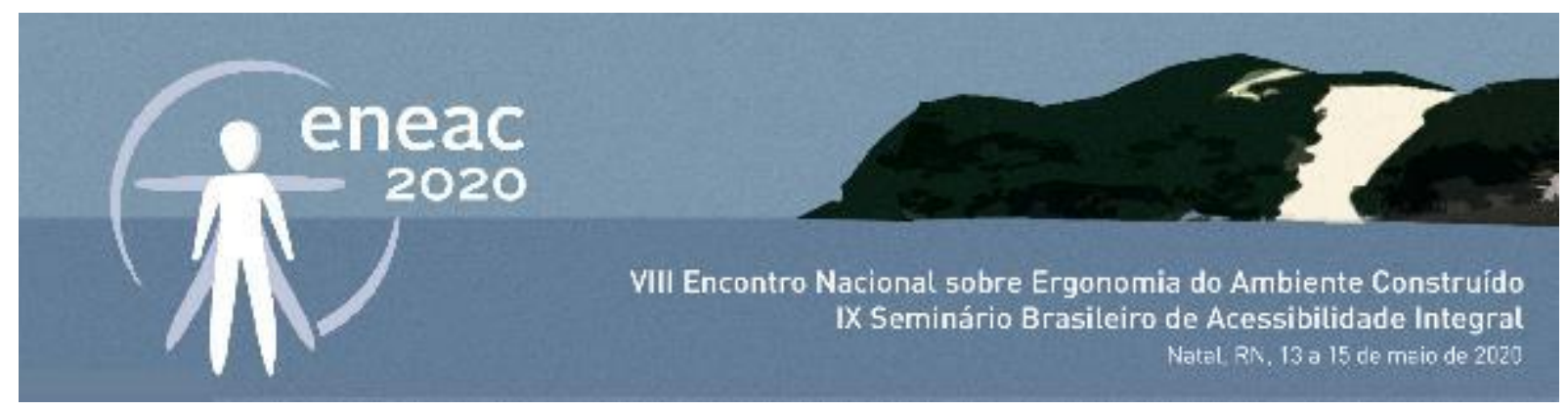

Obra $\mathrm{C}$ obteve mais posições de $1^{\circ}$ lugar (maiores resultados) em relação as outras obras, a Obra $\mathrm{D}$ ficou na $2^{\circ}$ posição, a Obra $B$ na $3^{\circ}$ posição e em último lugar a Obra $A$, cujos resultados nas avaliações oscilaram entre os menores valores comparados às demais obras analisadas. Entretanto numa análise comparativa entre a análise individual de obra e em relação ao conjunto de obras, observou-se outra configuração no posicionamento das obras. A Obra A ficou na última posição $\left(4^{\circ}\right)$, mesmo atingindo $68 \%$ da expectativa subjetiva dos usuários da sua obra, apenas a obra $\mathrm{C}$ manteve-se na primeira posição nas duas verificações. Tal variação também afetou as obras $B$ e $D$. Essas variações nas posições das obras indicam que o grupo de usuários de cada obra tem expectativas subjetivas específicas e diferenciadas dos demais grupos das outras obras.

Tabela 6 - Visualização em ordem decrescente de posicionamento de $1^{\circ}, 2^{\circ}, 3^{\circ}$ e $4^{\circ}$ lugar do resultado da avaliação de satisfação, considerando a comparação entre ambiente $x$ fator $x$ obras $(A, B, C, D)$.

\begin{tabular}{|c|c|c|c|c|c|c|c|c|c|c|c|c|}
\hline \multirow[t]{2}{*}{ Fatores analisados } & \multicolumn{3}{|c|}{ Obra A } & \multicolumn{3}{|c|}{ Obra B } & \multicolumn{3}{|c|}{ Obra C } & \multicolumn{3}{|c|}{ Obra D } \\
\hline & $\mathrm{V}$ & IS & $\mathrm{R}$ & $\mathrm{V}$ & IS & $\mathrm{R}$ & $\mathrm{V}$ & IS & $\mathrm{R}$ & $\mathrm{V}$ & IS & $R$ \\
\hline Função & 1 & 1 & 1 & 3 & 3 & 4 & 2 & 2 & 2 & 4 & 4 & 3 \\
\hline Forma & 1 & 2 & 4 & 3 & 3 & 2 & 2 & 1 & 1 & 4 & 4 & 3 \\
\hline Luz & 2 & 4 & 3 & 1 & 3 & 4 & 4 & 1 & 1 & 3 & 2 & 2 \\
\hline Som & 2 & 1 & 4 & 4 & 3 & 3 & 1 & 1 & 1 & 3 & 2 & 2 \\
\hline Conforto Térmico & 2 & 4 & 3 & 4 & 3 & 4 & 1 & 1 & 1 & 3 & 2 & 2 \\
\hline Conforto Visual & 2 & 4 & 4 & 4 & 3 & 3 & 1 & 1 & 2 & 3 & 2 & 1 \\
\hline Sig. Simbólico & 4 & 2 & 4 & 2 & 3 & 1 & 1 & 1 & 2 & 3 & 4 & 3 \\
\hline Mobiliário & 3 & 4 & 4 & 2 & 2 & 2 & 1 & 1 & 1 & 4 & 3 & 3 \\
\hline Resultado em ordem & \multicolumn{3}{|c|}{$4^{\circ}$ posição } & \multicolumn{3}{|c|}{$3^{\circ}$ posição } & \multicolumn{3}{|c|}{$1^{\circ}$ posição } & \multicolumn{3}{|c|}{$2^{\circ}$ posição } \\
\hline
\end{tabular}

$\mathrm{V}=$ vestiário, $\mathrm{IS}=$ instalação sanitária, $\mathrm{R}=$ refeitório.

\section{CONCLUSÕES}

A partir dos estudos exploratórios realizados, conclui-se que a percepção do ambiente construído da área de vivência pelo usuário da obra revela que num primeiro momento, a localização da área de vivência no canteiro de obras possui maior impacto para a satisfação do usuário da obra que a sua condição tecnológica do ambiente construído. $O$ usuário da obra prioriza o acesso adequado aos ambientes e a proximidade entre eles, sendo num segundo momento, dada a importância ao aspecto tecnológico empregado no ambiente construído. O desempenho da função do ambiente está associado à sua localização em relação ao conjunto de ambientes da área de vivência e a sua possibilidade de oferta múltipla (várias instalações daquele ambiente) e em diferentes locais da obra. A forma retangular dos ambientes refletiu em satisfação do usuário, estando relacionada com o conforto acústico (som) em que ambientes maiores propiciam maior conforto, e a sua localização na periferia do terreno da obra induz a melhores avaliações do ambiente. O conforto visual nos ambientes associa o uso de cores claras em revestimentos e as mobílias disponibilizadas pouco impactaram os usuários, de modo que apenas o uso do módulo contêiner para instalação sanitária gerou satisfação em relação aos equipamentos e mobílias ofertados em ambientes construídos em madeira bruta. O tempo de profissão na construção civil gerou impactos na percepção do usuário da obra, de modo que quanto maior o tempo de experiência na construção civil, menor a apropriação espacial com o ambiente da obra (significado simbólico). Observou-se que os grupo de trabalhadores das obras A, B, C e D possuem percepções coletivas diferenciadas entre si, refletindo a percepção do tipo de ambiente construído disponibilizado em cada obra pela empresa. Ou seja, o usuário da área de vivência não está inerte ao ambiente de trabalho, ele está em constante processo de avaliação ambiental. 


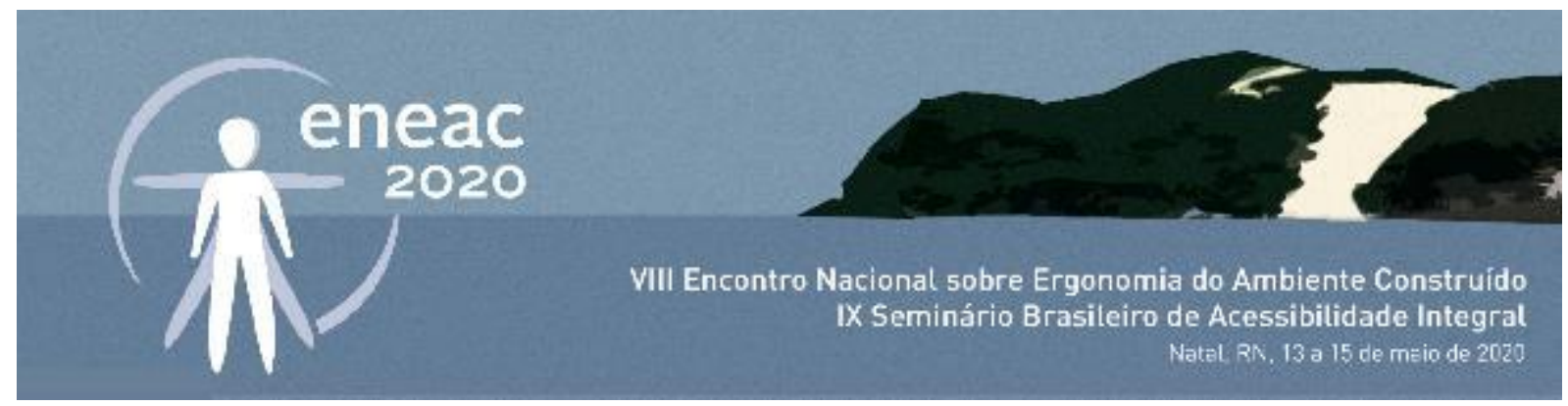

Portanto, essas informações científicas sobre o tema podem ser aplicadas na perspectiva de subsidiar discussões sobre a revisão da legislação, para instrumentalizar dados sobre o ambiente construído provisório de trabalho em obras, e para embasar o processo de planejamento do canteiro de obras e do projeto arquitetônico da área de vivência.

\section{REFERÊNCIAS}

BRASIL. Portaria no 3.214 do Ministério do Trabalho e Emprego. Institui as Normas Regulamentadoras no Brasil, (1978). Disponível em < http://www.mte.gov.br/legislacao/portarias/1978/p_19780608_3214.pdf> Acesso em 28/10/2017.

ELALI, Gleice Azambuja. Uma contribuição da psicologia ambiental à discussão de aspectos comportamentais da avaliação pós-ocupação. Pós. Revista do Programa de Pós-Graduação em Arquitetura e Urbanismo da FAUUSP, n. 20, p. 158-169, (2006).

_. Relações entre comportamento humano e ambiência: Uma reflexão com base na psicologia ambiental. Rio Grande do Norte: UFRN. (2010).

ESPINOZA, Juan Wilder Moore. Implementação de um programa de condições e meio ambiente no trabalho na indústria da construção para os canteiros de obras no sub-setor de edificações utilizando um sistema informatizado. Florianópolis. Dissertação (Mestrado). Programa de Pós-Graduação em Engenharia de Produção da Universidade Federal de Santa Catarina. (2002).

FERREIRA, Emerson de Andrade Marques; FRANCO, Luiz Sérgio. Metodologia para elaboração do projeto do canteiro de obras de edifícios. São Paulo. (1998).

FERRO, Sérgio; ARANTES, Pedro Fiori. Arquitetura e trabalho livre. Editora Cosac Naify. (2006).

IBGE Instituto Brasileiro de Geografia e Estatística. Planilhada sobre pessoas de 14 anos ou mais de idade ocupadas na Construção, baseada na Pesquisa Nacional por Amostra de Domicílios Contínua - Diretoria de Pesquisas, Coordenação de Trabalho e Rendimento -fornecida pelo CBIC - Câmara Brasileira da Indústria da Construção. (2019) Endereço do sítio: <http://www.cbicdados.com.br/menu/emprego/pnad-ibge-arquivos-resultados-brasil>. Acesso em 30/07/2019.

MELHADO, S. B. Qualidade do projeto na construção de edifícios: aplicação ao caso das empresas de incorporação e construção. Tese (Doutorado). Departamento de Engenharia de construção de edifícios da Escola Politécnica da Universidade de São Paulo, São Paulo. (1994).

MONT'ALVÃO, Claudia. A ergonomia do ambiente construído no Brasil. Um novo olhar para o projeto: a ergonomia no ambiente construído. Rio de Janeiro: 2AB (2011).

OKAMOTO, Juan. Percepção ambiental e comportamento. 2o Edição. IPSIS Gráfica e Editora S/A, São Paulo. (2002).

ONO, R.; ORNSTEIN, S. W.; OLIVEIRA, F. L.; GALVÃO, W. J. F. Avaliação Pós-Ocupação: Pré-Teste de Instrumentos para Verificação do Desempenho de Empreendimentos Habitacionais em Sistemas Construtivos Inovadores. Gestão e Tecnologia de Projetos, São Paulo, v. 10, n. 1, jan./jun. (2015).

PREISER, Wolfgang et. al. Post-Occupancy Evaluation. Nova lorque, Van Nostrand Reinhold. (1988).

ROMERO, Marcelo de Andrade; ORNSTEIN, Sheila Walbe. Avaliação Pós-ocupação: Métodos e Técnicas Aplicados à Habitação Social . Coleção Habitare ANTAC. Porto Alegre. (2003).

ROSSO, T. Racionalização da construção. São Paulo: Editora FAAUSP. (1980).

SAURIN, T. A., FORMOSO, C. T. Planejamento de canteiros de obra e gestão de processos. Recomendações Técnicas HABITARE, v. 3. Porto Alegre : ANTAC. (2006).

SILVA, H. N. Habitação em áreas de vivência e adequação de áreas de trabalho em três canteiros de obra em Criciúma -SC. 221f. Dissertação (Mestrado em Arquitetura e Urbanismo). Departamento de Arquitetura e Urbanismo da Universidade Federal de Santa Catarina, Florianópolis. (2014).

ZAPATEL, Juan. Elaboração de um Método para a Avaliação Pós-Ocupação (APO) de Edifícios Habitacionais situados nas Superquadras de Brasília. MSc. Diss. Universidade de São Paulo. (1992). 